Review

\title{
Circadian rhythms in glucose and lipid metabolism in nocturnal and diurnal mammals
}

\author{
Pawan Kumar Jha a, b, c, Etienne Challet b, c, Andries Kalsbeek a, c, d, * \\ ${ }^{a}$ Hypothalamic Integration Mechanisms, Netherlands Institute for Neuroscience, Amsterdam, The Netherlands \\ ${ }^{\mathrm{b}}$ Regulation of Circadian Clocks Team, Institute of Cellular and Integrative Neurosciences, UPR3212, Centre National de la Recherche Scientifique (CNRS), \\ University of Strasbourg, France \\ ${ }^{\mathrm{C}}$ International Associated Laboratory LIA1061 Understanding the Neural Basis of Diurnality, CNRS, France and the Netherlands \\ ${ }^{\mathrm{d}}$ Department of Endocrinology and Metabolism, Academic Medical Center (AMC), University of Amsterdam, The Netherlands
}

\section{A R T I C L E I N F O}

\section{Article history:}

Received 10 November 2014

Received in revised form

12 January 2015

Accepted 19 January 2015

Available online 7 February 2015

\section{Keywords:}

Suprachiasmatic nucleus

Circadian rhythm

Glucose metabolism

Lipid metabolism

Autonomic nervous system

Hypothalamus

\begin{abstract}
A B S T R A C T
Most aspects of energy metabolism display clear variations during day and night. This daily rhythmicity of metabolic functions, including hormone release, is governed by a circadian system that consists of the master clock in the suprachiasmatic nuclei of the hypothalamus (SCN) and many secondary clocks in the brain and peripheral organs. The SCN control peripheral timing via the autonomic and neuroendocrine system, as well as via behavioral outputs. The sleep-wake cycle, the feeding/fasting rhythm and most hormonal rhythms, including that of leptin, ghrelin and glucocorticoids, usually show an opposite phase (relative to the light-dark cycle) in diurnal and nocturnal species. By contrast, the SCN clock is most active at the same astronomical times in these two categories of mammals. Moreover, in both species, pineal melatonin is secreted only at night. In this review we describe the current knowledge on the regulation of glucose and lipid metabolism by central and peripheral clock mechanisms. Most experimental knowledge comes from studies in nocturnal laboratory rodents. Nevertheless, we will also mention some relevant findings in diurnal mammals, including humans. It will become clear that as a consequence of the tight connections between the circadian clock system and energy metabolism, circadian clock impairments (e.g., mutations or knock-out of clock genes) and circadian clock misalignments (such as during shift work and chronic jet-lag) have an adverse effect on energy metabolism, that may trigger or enhancing obese and diabetic symptoms.
\end{abstract}

() 2015 Elsevier Ireland Ltd. All rights reserved.

\section{Contents}

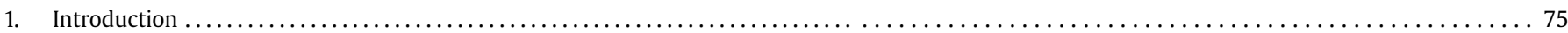

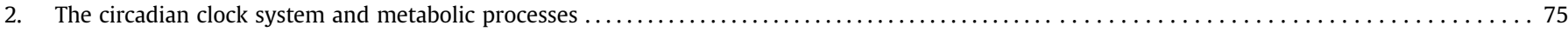

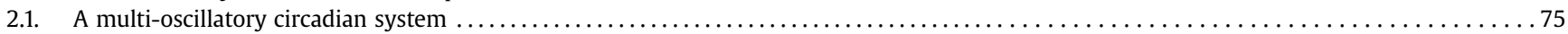

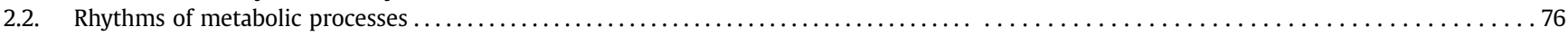

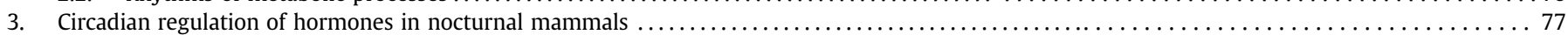

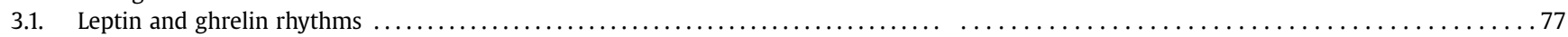

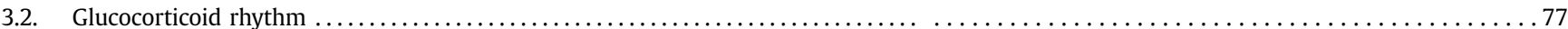

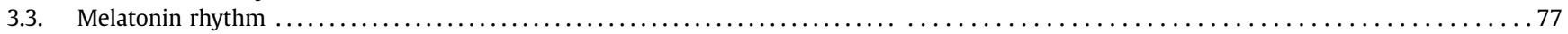

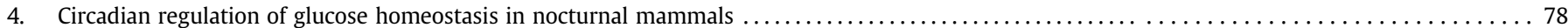

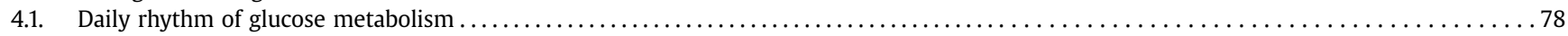

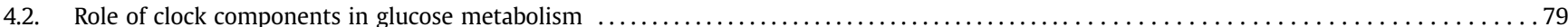

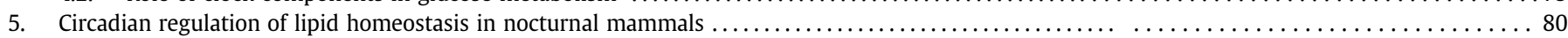

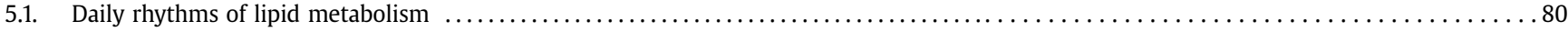

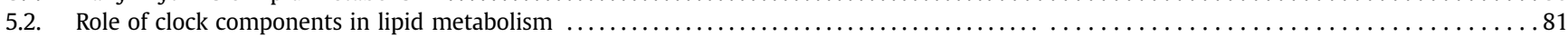

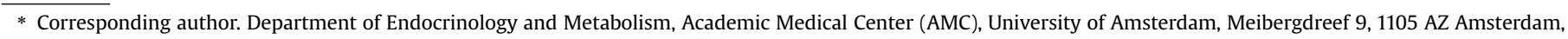
The Netherlands. Tel.: +3120 5661765; fax: +31206917682.

E-mail address: a.kalsbeek@amc.uva.nl (A. Kalsbeek). 


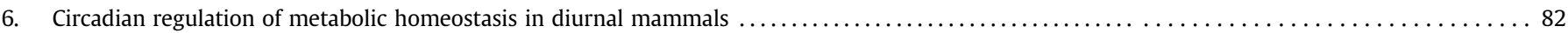

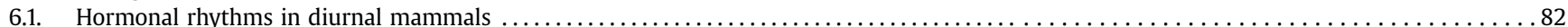

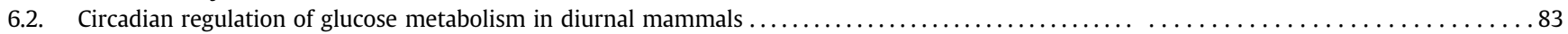

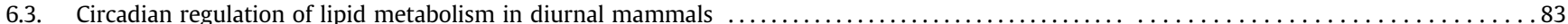

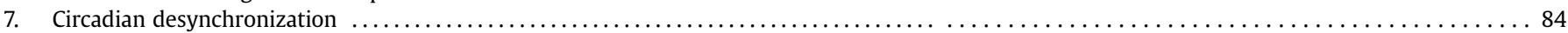

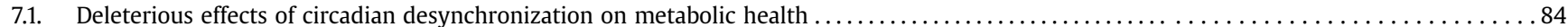

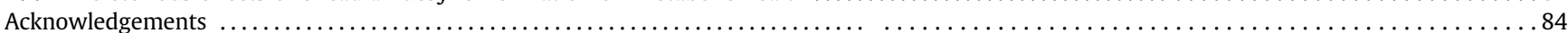

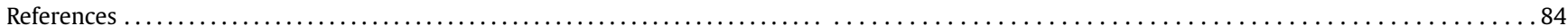

\section{Introduction}

Light, temperature and food availability on earth cycle with a 24-h period according to the rotation of earth around its own axis. Living organisms have evolved by adapting to these periodic changes in their environment. During evolution, almost all organisms acquired an internal time-keeping system, called circadian (from the Latin words circa and dies meaning about and a day, respectively) clock, in order to anticipate this variable, albeit mostly predictable, environment. Circadian clocks are characterized by three properties: (1) they generate rhythms with a period of $\sim 24 \mathrm{~h}$ that persist in the absence of a light-dark cycle (i.e., self-sustained oscillations); (2) this circadian period length is stable over a wide range of temperatures (temperature compensation); and (3) they are able to be synchronized with environmental cues or Zeitgebers (i.e., time-givers), such as light-dark cycle, ambient temperature cycle and food availability (Johnson et al., 2004). From cyanobacteria to humans, the circadian clocks regulate many metabolic and physiological processes in a rhythmic way in order to accomplish the fluctuating demands over the day in energy use and supply. In mammals, energy intake and expenditure vary according to their sleep/wake and fasting/feeding periods, the timing of which depends on whether the species is diurnal or nocturnal. In both cases, the period of wakefulness and feeding coincides with a high metabolic, anabolic and thermogenic state, whereas sleep and fasting correspond to a state of low metabolism and catabolism (Alberts et al., 2006; Yang et al., 2010). Food intake during the active period ensures the uptake and storage of energy substrates such as carbohydrates, lipids and amino acids necessary to maintain a high metabolic rate, while during the resting period, stored substrates such as glycogen and fat are metabolized to maintain basal energy expenditure.

In mammals, the hypothalamus controls major components of energy homeostasis, including food and water intake, thermoregulation and metabolism, as well as sleep and arousal. Lesion and grafting studies identified an anterior hypothalamic area above the optic chiasm, called suprachiasmatic nuclei (SCN), as the central clock which controls the behavioral and physiological day/night rhythms associated with energy homeostasis, including sleep/ wake, fasting/feeding, glucose metabolism and insulin secretion (Dibner et al., 2010; Weaver, 1998). Circadian regulation of energy metabolism is well documented. For example, plasma glucose concentration, glucose tolerance and insulin sensitivity vary throughout the day (Kalsbeek et al., 2014). Evidence from SCN lesions and denervation of autonomic projections has established the role of the SCN via the autonomous nervous system in the circadian modulation of glucose homeostasis (Kalsbeek et al., 2014). Furthermore, many metabolic pathways involved in glucose and lipid metabolism are rhythmically coordinated by circadian clocks (Bugge et al., 2012; Delezie et al., 2012; Grimaldi et al., 2010; Panda et al., 2002; Zhang et al., 2010). In this review, we will summarize recent advances in understanding the role of circadian clocks in the daily regulation of energy metabolism.

\section{The circadian clock system and metabolic processes}

\subsection{A multi-oscillatory circadian system}

The daily rhythm of various biological processes, ranging from behavior to gene expression, is mediated by a synchrony between environmental cues and the circadian timing system. Exposure to a constant environment results into a free-run of these endogenous biological rhythms, characterized by periodicities slightly shorter or longer than $24 \mathrm{~h}$, depending on the species considered (Aschoff, 1965; Pittendrigh and Daan, 1976). Light is the primary environmental cue that entrains the main circadian clock in the SCN, thus allowing internal rhythms to be adjusted exactly to a 24 hour period on a day-to-day basis. In mammals, retinal ganglion cells perceive the ambient light and transduce this photic signal to the SCN through the retinohypothalamic tract (Lucas et al., 2012; Moore and Lenn, 1972). Through the retinohypothalamic tract the circadian rhythm generated within SCN neurons is entrained to an overt 24-hour rhythm and these coordinated outputs are conveyed to the rest of the body via behavioral, neuroendocrine, and autonomic pathways (Kalsbeek et al., 2006; Mohawk et al., 2012).

The molecular oscillations of the SCN depend on several specific genes, called clock genes. Circadian rhythmicity is based on rhythmic expression of core clock genes and their autoregulatory feedback transcriptional/translational loops (Fig.1). The core clock machinery is structured with positive transcriptional regulators, including BMAL1/CLOCK and RORs, and negative regulators such as PERs (PER1-3), CRYs (CRY1-2) and REV-ERBs. BMAL1 binds with CLOCK and forms heterodimers which activate the transcription of the negative PER and CRY regulators, thus defining a positive loop (Reppert and Weaver, 2002). PERs and CRYs accumulate in the cytoplasm and form complexes which translocate into the nucleus to inhibit their own transcription along with other BMAL1/CLOCKdriven transcription, such as that of the clock-controlled genes, thereby forming a negative loop (Mohawk et al., 2012). An additional negative loop in this molecular network is contributed by the nuclear receptors REB-ERB $\alpha$ and $-\beta$. REV-ERBs bind to the ROR response element (RRE) of BMAL1 and CLOCK promoters and repress their transcription, whereas in counterbalance to REV-ERBs inhibition, ROR $\alpha / \beta / \gamma$ also bind on the RRE of BMAL1 and induce its transcription (Crumbley and Burris, 2011; Guillaumond et al., 2005; Preitner et al., 2002). The circadian rhythms generated by this molecular clock machinery get fine-tuned by environmental cues. In particular, light can synchronize the SCN neurons via a cascade of transcriptional activation. In response to photic inputs from retinal ganglion cells, glutamate and pituitary cyclase-activating peptide are released in the ventral region of the SCN, leading to transcriptional induction of clock gene expression through chromatin remodelling (Dibner et al., 2010). Of note, the molecular clock in the SCN works at the same astronomical times in diurnal and nocturnal species, and the mechanisms underlying photic resetting are essentially similar in terms of temporal sensitivity and direction of light-induced phase shifts between both categories of mammals 


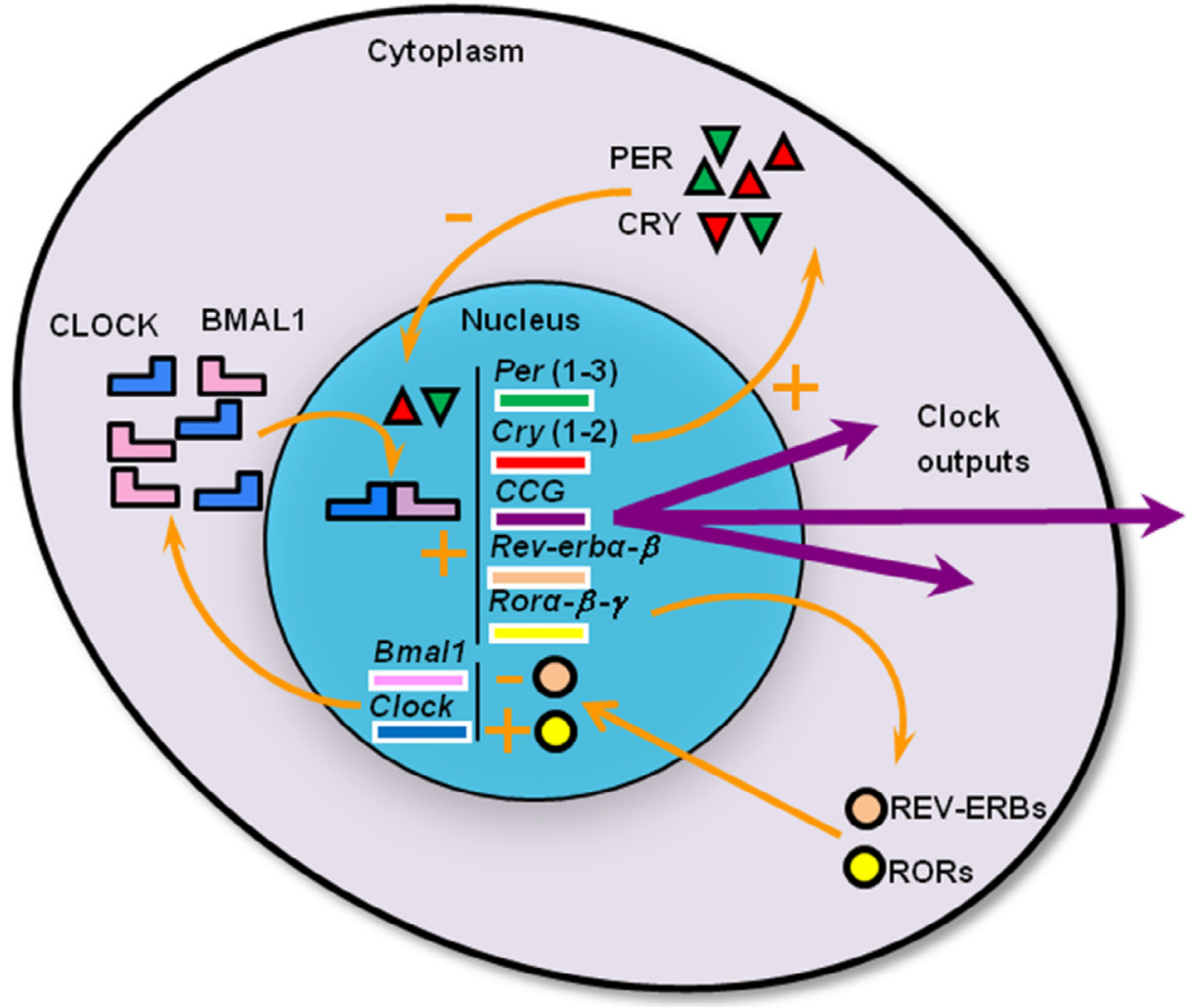

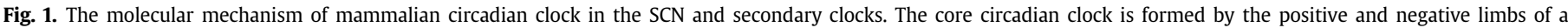

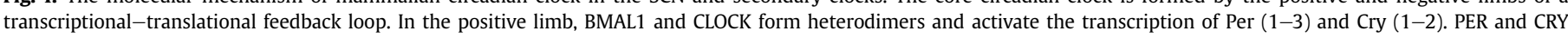

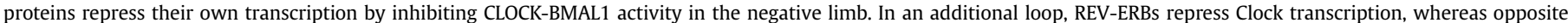

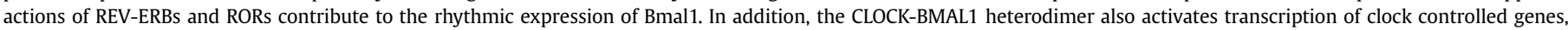

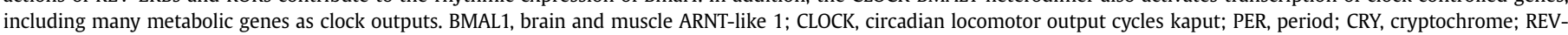
ERBs, reverse viral erythroblastosis oncogene products; RORs, retinoic acid-related orphan receptors; CCG, Clock controlled genes.

Adapted from Crumbley and Burris (2011) and Mohawk et al. (2012).

(Challet, 2007). These findings suggest that the distinction between nocturnal and diurnal animals likely relies on neural mechanisms operating downstream of the SCN clock (Kalsbeek et al., 2008b).

Demonstration of rhythmic clock gene expression in cells and tissues throughout the body, and persistence of these rhythms in cultured cells, revealed the presence of secondary circadian clocks in brain regions outside of the SCN, such as the arcuate (ARC) and the dorsomedial hypothalamic nuclei $(\mathrm{DMH})$, as well as in most peripheral organs, including those essential for energy homeostasis, such as liver, kidney, pancreas, skeletal muscle and adipose tissue (Abe et al., 2002; Balsalobre et al., 1998; Guilding and Piggins, 2007; Yamazaki et al., 2000; Yoo et al., 2004). In the peripheral organs, cellular metabolism is tightly connected to the circadian clock mechanism, in part via interactions with cellular energy sensors such as sirtuin 1 (SIRT1) and $5^{\prime}$ adenosine monophosphateactivated protein kinase (AMPK). For instance, SIRT1 modulates the transcription of several clock genes and promotes deacetylation of clock proteins (Asher et al., 2008; Nakahata et al., 2008). Besides its numerous effects on intracellular metabolism, including SIRT1 activity, AMPK also modulates the molecular clockwork by destabilizing PER2 and CRY1 proteins (Lamia et al., 2009; Um et al., 2007).

Although the basic molecular components of the central clock are conserved in these extra-SCN oscillators, their self-sustained rhythmicity is less robust than in the central clock. Using Per1 luciferase rat explants, Yamazaki et al. (2000) showed that circadian rhythmicity in peripheral organs, such as lungs, liver and skeletal muscles, starts to dampen within 1 week, whereas the SCN cycle up to at least 32 days. Dampening within a few cycles has also been reported from explants of various brain areas other than the SCN (Abe et al., 2002; Abraham et al., 2005; Guilding and Piggins, 2007). Of note, Yoo et al. reported persistent, self-sustained circadian oscillations of PER2 expression for more than 20 days in lungs and liver explants of PER2-luciferase transgenic mice (Yoo et al., 2004). SCN lesions in these animals do not cause disappearance of PER2 rhythmic expression, although they do lead to asynchrony of phase between peripheral organs of the same individuals. This study specifies the role of the SCN as a conductor which drives rhythms of peripheral clocks by maintaining phase coherence among organs.

\subsection{Rhythms of metabolic processes}

Energy intake and expenditure processes fluctuate over a $24 \mathrm{~h}$ period in association with sleep/wake, activity/rest and fasting/ feeding cycles. Both diurnal and nocturnal animals consume food and water mostly during their wake period, corresponding to either day or night, respectively. Lesion studies have shown that the SCN clock regulates daily rhythmicity of food and water intake (Nagai et al., 1978; Stephan and Zucker, 1972). Like energy intake, energy expenditure in mammals also displays circadian rhythmicity through daily variations in the metabolic rate (Aschoff et al., 1986; Daan et al., 2013). Mammals use ingested and stored calories for the maintenance of basal metabolic rate, resting metabolic rate, core body temperature and physical activities. A significant proportion of energy expenditure goes to the maintenance of the basal metabolic rate which directly affects body temperature. Accordingly, 
nocturnal rodents show elevated energy expenditure and body temperature in their wake/feeding period in association with behavioral arousal, increased locomotion and food consumption at night (Alberts et al., 2006; Yang et al., 2010). Both core body temperature and energy expenditure display rhythms over the daily $24 \mathrm{~h}$ periods that are oppositely phased between diurnal and nocturnal animals (Cuesta et al., 2009; Krauchi and Wirz-Justice, 2001; Piccione et al., 2005; Zulley et al., 1981). The other determinants of energy expenditure are behavioral arousal and physical exercise, two activities that are also in anti-phase between nocturnal and diurnal species. These parameters also contribute to the daily increase in metabolic rate and body temperature during either the diurnal or nocturnal activity phase. Moreover, both behavioral arousal and exercise feedback to the circadian clock in the SCN upon which they act as potent Zeitgebers (Hughes and Piggins, 2012).

Alterations in feeding pattern can desynchronize the metabolic rhythms and eventually disturb energy homeostasis. Feeding regular chow diet during daytime alters energy balance in nocturnal mice, as compared to animals fed only during the night (Bray et al., 2013). When mice are forced to eat a high-fat diet during the light phase or at the end of the night, metabolic perturbations occur, inducing increased adiposity and decreased glucose tolerance (Arble et al., 2009; Bray et al., 2010). Furthermore, restricting highfat feeding only to the active period of animals attenuates body weight gain and improves glucose and lipid metabolism (Hatori et al., 2012; Tsai et al., 2013). Another study suggests that the risk of metabolic impairments is diminished when caloric intake during the resting period is lower than during the active period (Haraguchi et al., 2014). Concomitant with the metabolic perturbations that occur with the temporal shift in feeding pattern, differential shifts in the phase of circadian gene expression also occur in metabolically active tissues, such as liver, heart, skeletal muscle, and adipose tissue, while the SCN remain unaffected (Damiola et al., 2000; Stokkan et al., 2001). These shifts in peripheral organs result in an asynchrony between the central clock and the peripheral clocks. Restricted feeding outside of an animal's usual activity period not only causes desynchrony between SCN and peripheral organs, but likely also among the peripheral metabolic organs themselves, including liver, skeletal muscle and adipose tissue (Bray et al., 2013).

\section{Circadian regulation of hormones in nocturnal mammals}

\subsection{Leptin and ghrelin rhythms}

Endocrine signals from the periphery exert their effects on the daily energy balance by transmitting signals back to the brain in a circadian-dependent manner. These signals, such as ghrelin and adipokines, provide information to the brain about the presence or absence of peripheral stores or demands in energy. Leptin is an adipokine primarily secreted by the white adipose tissue and transported to, among others, the ARC where it inhibits NPY/AgRP neurons and activates POMC/CART neurons, thus resulting in reduced food intake (Kalra et al., 2003; Sobrino Crespo et al., 2014). The daily rhythm of leptin release is under the control of the SCN clock via its autonomic input to the adipose tissue. Indeed, the leptin rhythm, which peaks in early night in laboratory rats, persists in adrenalectomized animals or during a 6-meals-per-day schedule, but disappears after an SCN lesion (Kalsbeek et al., 2001). The anorectic action of leptin is antagonized by ghrelin which is a hormone primarily secreted by the oxyntic cells of the stomach. Ghrelin evokes feeding primarily through activation of neurons in the ARC, resulting in increased release of NPY and AgRP in the paraventricular nucleus of the hypothalamus (PVN) and other target hypothalamic structures (Kalra et al., 2003; Patton and Mistlberger, 2013). Plasma levels of ghrelin oscillate according to the feeding cycle. In nocturnal rodents, plasma levels of ghrelin increase during the resting period (i.e., light phase) in anticipation of food intake (Bodosi et al., 2004; Sanchez et al., 2004), which makes this hormone a putative candidate for regulating the circadian food anticipatory rhythm (Patton and Mistlberger, 2013). Ghrelin also feeds back to the SCN by affecting clock gene expression, producing phase shifts in the fasted state and attenuating light resetting of the SCN (Yannielli et al., 2007; Yi et al., 2008). Therefore, ghrelin may prove to be an endocrine signal that helps to communicate between the stomach and the central clock.

\subsection{Glucocorticoid rhythm}

Efferent signals from the SCN help to maintain the daily variations of hormones via neuroendocrine and autonomic outputs which can, in turn, provide temporal cues to targets in peripheral and cerebral tissues. The PVN is an important relay center for energy homeostasis which receives nervous and diffusible signals from the SCN over the day in a time-dependent manner (Buijs et al., 2003; Tousson and Meissl, 2004). Neurons containing corticotrophin-releasing hormone (CRH) in the PVN are actually controlled on a daily basis by a balance between inhibitory and stimulatory inputs from the SCN. In turn, CRH triggers a secretion of adrenocorticotropic hormone (ACTH) from the pituitary which participates in the daily rhythms of plasma glucocorticoids (GC) (Kalsbeek et al., 2008b; Verhagen et al., 2004). In nocturnal rodents, the peak of plasma GC (corticosterone is the main GC in rats) is phase-locked with the activity onset. Circadian regulation of GC secretion from the adrenal gland plays an important role in the regulation of energy metabolism. For example, excess of cortisol leads to hyperglycemia, hypertension, sleep disturbance, body weight gain and other metabolic impairments (Carroll and Findling, 2010). GC signaling is critical for maintaining fasting glucose by stimulating hepatic gluconeogenesis (Lin and Accili, 2011). Furthermore, abnormal activation of GC has diabetogenic consequences, including hyperglycemia (van Raalte et al., 2009). Other studies suggest that GC also directly affect clock gene expression in metabolically active tissues, such as liver and kidney, whereas they can trigger rhythmic gene expression in the liver of SCN-lesioned animals (Balsalobre et al., 2000; Oishi et al., 2005; Reddy et al., 2007). By contrast, in the white adipose tissue and liver, adrenalectomy abolishes many daily rhythms in metabolic/adipokine gene expression, but not clock gene expression (Oishi et al., 2005; Su et al., 2014). Moreover, besides clock mechanisms, the GC rhythm is profoundly affected by stress and stressful events occurring during the daily trough of plasma GC (i.e., late night and morning in nocturnal species) will therefore mask the endogenous rhythm of GC. Also, ambient light can acutely modulate secretion of GC. In nocturnal mice and rats, light at different times of day enhances corticosterone release via sympathetic pathways, without inducing ACTH release and independently of the SCN (Buijs et al., 1999; Ishida et al., 2005; Kiessling et al., 2014).

\subsection{Melatonin rhythm}

The daily melatonin rhythm is probably one of the evolutionary oldest hormonal outputs of the circadian timing system (Schippers and Nichols, 2014). In mammals, the SCN tightly regulate the rhythmic synthesis and release of melatonin from the pineal gland. Nocturnal release of melatonin can provide temporal cues to target tissues expressing melatonin receptors. It can also feed back to the SCN clock by activating its receptors expressed therein (Pevet and Challet, 2011). Rhythmic release of GABA from the SCN inhibits 
sympathetic input from the PVN to the pineal gland during the light period, whereas during the dark period a constant glutamatergic stimulatory input prevails in the absence of the inhibitory GABAergic input and, therefore, leads to secretion of melatonin (Kalsbeek and Fliers, 2013). Furthermore, light exposure at night acutely inhibits synthesis and secretion of pineal melatonin (Redlin, 2001). Consistent experimental results in laboratory rats show that the absence of rhythmic release of melatonin in blood circulation leads to chronodisruption of functions associated with energy metabolism. In particular pinealectomy, suppressing the nocturnal rise in melatonin, disturbs the $24 \mathrm{~h}$ rhythm of plasma glucose concentration (la Fleur et al., 2001b) and eliminates the daily rhythm of glucose-induced insulin secretion (Picinato et al., 2002). In addition, impaired glucose tolerance, decreased adipose cell responsiveness to insulin and a reduction in GLUT4 content in muscle and adipose tissue have been reported after pinealectomy (Lima et al., 1998).

\section{Circadian regulation of glucose homeostasis in nocturnal mammals}

Glucose is the fundamental energy substrate, being metabolized by nearly all known living organisms to sustain their life. As energy requirements of the organism fluctuate in a time-of-daydependent fashion, diurnal oscillations in glucose metabolism are due in part to daily changes in glucose utilization. For this review, we will focus on the circadian regulation of glucose homeostasis and on the disruptive consequences of altered clock functioning on glucose metabolism.

\subsection{Daily rhythm of glucose metabolism}

The glucose concentration in plasma results from coordinated regulation of glucose input (food intake, hepatic glucose production) and its utilization (uptake by skeletal and cardiac muscles, and adipose tissues). A daily rhythm in plasma glucose concentrations has been reported by many authors. But the first evidence for the involvement of the SCN in glucose homeostasis came from the fact that bilateral SCN lesions abolished plasma glucose and insulin rhythms and eliminated the differential day and night response to 2 deoxy-glucose, an inhibitor of glucose utilization (Nagai et al., 1994). Since the rhythms of plasma glucose and insulin concentrations are in phase with the feeding rhythm and insulin secretion is mainly triggered by increased blood glucose in response to food intake, the rhythms of glucose and insulin were long thought to be regulated indirectly through the feeding rhythm. The first evidence for a direct involvement of the SCN in glucose metabolism came from rats trained to a 6 -meals-per-day feeding schedule (i.e., one food access of $10 \mathrm{~min}$ every $4 \mathrm{~h}$ ), as these animals still displayed larger glucose and insulin responses in the evening (Kalsbeek and Strubbe, 1998). Furthermore, the persistence of the daily rhythm of plasma glucose concentration in rats fasted or challenged with the 6-meal schedules and its elimination after SCN lesions clearly showed the involvement of the SCN in the regulation of plasma glucose concentration, independently of feeding (La Fleur et al., 1999). On the other hand, plasma insulin and glucagon concentrations increase equally after every meal during the 6-meal feeding schedule, indicating that these hormones do not contribute largely to the genesis of glucose rhythm (La Fleur et al., 1999; Ruiter et al., 2003). The daily rhythm of plasma glucose concentrations in rats shows its acrophase at the end of the light period, anticipating the activity increase at dark onset (Cailotto et al., 2005; Challet et al., 2004; La Fleur et al., 1999). Intravenous glucose tolerance tests at different times of the day demonstrated that glucose disposal shows a daily rhythm which is highest at the beginning of the dark period (la Fleur et al., 2001a). Since the glucose concentration in the circulation results from both glucose production and disposal and knowing that both the plasma glucose concentration and glucose disposal are highest at the beginning of activity period, glucose production should be also highest at this point. Thus, in nocturnal animals, glucose production and utilization both increase at the beginning of the activity period and show a clear daily rhythmicity.

Delineation of synaptic connections between SCN and liver through both branches of autonomic nervous system and their involvement in the hyperglycemia induced in animals whose SCN was electrically stimulated, supported the view that the SCN-autonomic nervous system axis is implicated in the regulation of glucose homeostasis (Fujii et al., 1989; Nagai et al., 1988). The effect of hepatic denervations in the rat confirmed the role of SCN in the generation of daily rhythmicity in plasma glucose concentration via its influence on the autonomic innervation to the liver (Cailotto et al., 2005; Kalsbeek et al., 2004). The SCN do not directly target the autonomic motor neurons but instead, they transmit their signals to the autonomic branches through hypothalamic relay structures. The PVN being one of the most important hubs in that respect, because they receive signals from $\mathrm{SCN}$, they integrate and convey them to the peripheral organs via autonomic projections to brainstem and spinal cord (Buijs and Kalsbeek, 2001; Hosoya et al., 1991). The communication between SCN and PVN for controlling plasma glucose concentration has been revealed by administration of GABA $A_{A}$ antagonists and NMDA agonists in the vicinity of the PVN (Kalsbeek et al., 2004). The results indicated that the hyperglycemia induced by activation of PVN neurons is basically independent of insulin and corticosterone release, while glucagon release might be involved. Moreover, the hyperglycemic effect of the $\mathrm{GABA}_{A}$ antagonist and NMDA was completely prevented by a selective denervation of sympathetic, but not parasympathetic, inputs to the liver (Kalsbeek et al., 2004). Repeating these experiments at different times of the day, as well as in SCN-ablated rats, confirmed that the $\mathrm{SCN}$ is the main source of these GABAergic and glutamatergic inputs to the PVN. Collectively, these findings demonstrated that activation of PVN neurons results in hyperglycemia through activation of sympathetic inputs to the liver and that pre-autonomic neurons in the PVN are controlled by a balance between these inhibitory and excitatory inputs in order to maintain glucose homeostasis (Kalsbeek et al., 2008a). Besides SCN control, environmental cues, such as stressful events and ambient light, can also modulate plasma glucose levels. For instance, stress-induced hyperglycemia may blunt the circadian rhythm of plasma glucose. Moreover, plasma glucose in nocturnal rats is increased by light exposure at different times of the day, probably via sympathetic pathways (Challet et al., 2004). The perifornical (PF) and lateral hypothalamic areas ( $\mathrm{LH}$ ) are other targets of SCN output which harbor metabolic neuropeptides, such as orexin and melaninconcentrating hormone (MCH) (Abrahamson et al., 2001; Deurveilher and Semba, 2005; Valassi et al., 2008). Orexin, which is expressed according to a day/night rhythm, is known to be involved in arousal, food intake and energy metabolism (Karasawa et al., 2014; Tabuchi et al., 2014; Zhang et al., 2004). The activity of orexin neurons in the $\mathrm{PF} / \mathrm{LH}$ seems to be under the control of rhythmic GABA-mediated inhibition such that orexin release is low during the sleeping period and high during the wake state (Alam et al., 2005). Activation of orexinergic neurons by administration of a $\mathrm{GABA}_{\mathrm{A}}$ antagonist in the PF not only increases arousal, but also enhanced hepatic glucose production, an effect that could largely be prevented by intracerebroventricular pre-treatment with an orexin-1 receptor antagonist (Yi et al., 2009). The activity of orexinergic neurons primarily depends on sleep and arousal states, but its sympatho-excitatory effects also regulate cardiovascular 


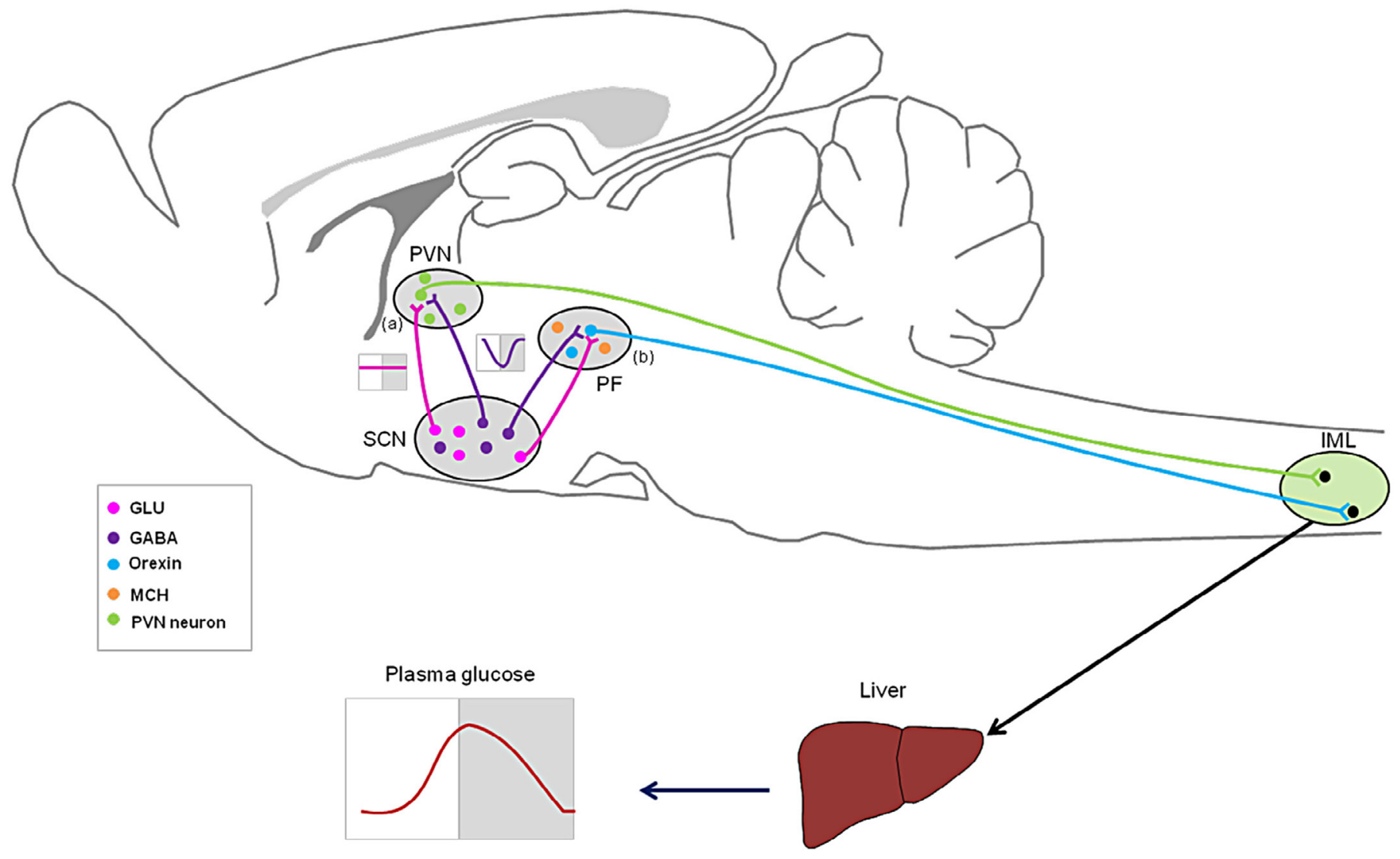

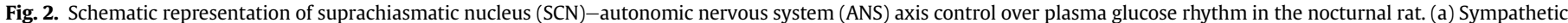

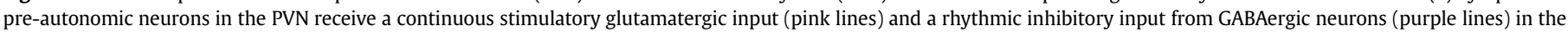

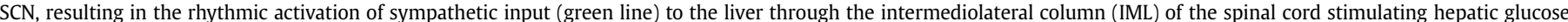

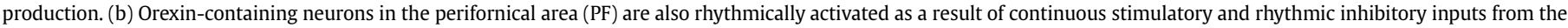

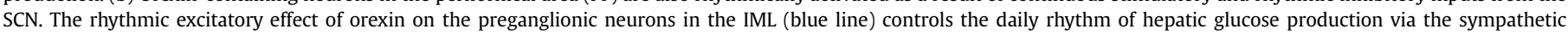
innervation to the liver.

Adapted from Kalsbeek et al. (2010).

function, thermoregulation, and energy metabolism, leading to appropriate metabolic adaptation during both sleep and arousal (Grimaldi et al., 2014). To sum up, the SCN clock appears to regulate rhythmicity of glucose production and utilization, as well as insulin release and insulin sensitivity, most likely via projections of the autonomic nervous system to tissues such as liver, muscle and pancreas (Fig. 2).

\subsection{Role of clock components in glucose metabolism}

Loss of function of CLOCK or BMAL1, two positive regulators of the molecular clockwork, leads to several metabolic abnormalities. Homozygous Clock mutant mice show an attenuated daily rhythm of food intake, as well as hyperphagia and increased adiposity. In addition, they develop metabolic impairments such as hyperglycemia, dislipidemia, hypoinsulinemia, hepatic steatosis and reduced gluconeogenesis (Rudic et al., 2004; Turek et al., 2005). On the other hand, the Clock mutation in melatonin-proficient mice does not lead to obesity, but does impair glucose tolerance (Kennaway et al., 2007). Furthermore, the Clock gene mutation results in dampened oscillations of hepatic glycogen and glycogen synthase 2 (Gys2), the rate limiting enzyme of glycogenesis, expression (Doi et al., 2010). Mice lacking Bmal1 in all tissues show impaired glucose tolerance and abnormal energy balance whereas circadian expression of Glut2 is abolished in hepatocytes of liverspecific Bmal1 $\mathrm{KO}$ mice, in association with relative hypoglycemia during the daily fasting period (i.e., light period) (Lamia et al., 2008). Global Bmal1 KO mice are also unable to trigger liver gluconeogenesis (Rudic et al., 2004). Mice lacking Bmal1 specifically in the pancreas or in $\beta$ cells develop diabetes mellitus due to defective $\beta$-cell functioning. These mice show elevated plasma glucose levels, glucose intolerance and loss of glucose-stimulated insulin secretion from $\beta$ cells. However, insulin content in the pancreatic islets of $\mathrm{KO}$ mice is similar to that of wild-type mice, suggesting that insulin secretion, but not its synthesis, is altered in the Bmal1 mutant mice (Lee et al., 2013; Marcheva et al., 2010; Sadacca et al., 2011).

Glucose homeostasis is also affected by the genetic loss of core clock genes other than Clock and Bmal1. Disruption of Per2 expression results in reduced fasting glycemia, altered glycogen accumulation in the liver, enhanced glucose-induced insulin secretion and impaired gluconeogenesis (Schmutz et al., 2010; Zani et al., 2013; Zhao et al., 2012), although Feillet et al. (2006) detected no change in the daily variations of liver glycogen in Per2 mutant mice. Mice deficient in Per2 also may have dampened corticosterone rhythms (Yang et al., 2009), but other investigations reported unaltered or increased corticosterone rhythms in Per2 mutants (Dallmann et al., 2006). Glucose metabolism is also severely affected in Cry mutant mice. Genetic loss of both Cry 1 and Cry 2 $\left(\right.$ Cry $\left.1^{-1-} / \mathrm{Cry}^{-1-}\right)$ results in elevated blood glucose levels in response to acute feeding after an overnight fast, and delayed disposal of glucose in a glucose tolerance test (Lamia et al., 2011). A 
Table 1

Changes in glucose and lipid metabolism in clock gene mutants and knock-outs.

\begin{tabular}{|c|c|c|c|c|}
\hline Gene & Type of invalidation & Impact on glucose metabolism & Impact on lipid metabolism & Reference \\
\hline \multirow[t]{7}{*}{ Clock } & Global $\Delta 19$ mutation & $\begin{array}{l}\text { Reduced gluconeogenesis and } \\
\text { increased insulin sensitivity }\end{array}$ & & Rudic et al. (2004) \\
\hline & Global $\Delta 19$ mutation & Hyperglycemia and hypoinsulinemia & $\begin{array}{l}\text { Hypertriglyceridemia and increased } \\
\text { serum cholesterol }\end{array}$ & Turek et al. (2005) \\
\hline & Global $\Delta 19$ mutation & Decreased glucose tolerance & Reduced plasma free fatty acids & Kennaway et al. (2007) \\
\hline & Global $\Delta 19$ mutation & $\begin{array}{l}\text { Damped oscillation of hepatic } \\
\text { glycogen and glycogen synthase } 2 \text { (Gys 2) }\end{array}$ & & Doi et al. (2010) \\
\hline & Global $\Delta 19$ mutation & $\begin{array}{l}\text { Increased plasma glucose level } \\
\text { and reduced glucose tolerance }\end{array}$ & & Marcheva et al. (2010) \\
\hline & Global $\Delta 19$ mutation & & $\begin{array}{l}\text { Hypertriglyceridemia and high expression } \\
\text { of microsomal triglyceride transfer protein } \\
\text { (MTP) }\end{array}$ & Pan et al. (2010) \\
\hline & Global $\Delta 19$ mutation & & $\begin{array}{l}\text { Reduced plasma free fatty acid increased } \\
\text { cholesterol }\end{array}$ & Shostak et al. (2013) \\
\hline \multirow[t]{5}{*}{ Bmal1 } & Global knock-out & Glucose intolerance & & Lamia et al. (2008) \\
\hline & Liver-specific knock-out & Increased glucose tolerance & & Lamia et al. (2008) \\
\hline & Global knock-out & Increased insulin sensitivity & Elevated plasma triglycerides & Rudic et al. (2004) \\
\hline & pancreas-specific knock-out & $\begin{array}{l}\text { Impaired glucose tolerance } \\
\text { and hypoinsulinemia }\end{array}$ & & Marcheva et al. (2010) \\
\hline & Global knock-out & & Elevated circulating free fatty acids & Shimba et al. (2011) \\
\hline \multirow[t]{4}{*}{ Per2 } & Global Brdm1 mutation & $\begin{array}{l}\text { Reduced fasting glycemia and altered } \\
\text { glycogen storage }\end{array}$ & & Zani et al. (2013) \\
\hline & Global Brdm1 mutation & Hypoglycemia & & Schmutz et al. (2010) \\
\hline & Global Brdm1 mutation & $\begin{array}{l}\text { Hyperinsulinemia, increased glucose } \\
\text { tolerance and insulin sensitivity }\end{array}$ & & Zhao et al. (2012) \\
\hline & Global knock-out & & $\begin{array}{l}\text { Reduced plasma triglycerides and free } \\
\text { fatty acids }\end{array}$ & Grimaldi et al. (2010) \\
\hline $\operatorname{Per} 1 / 2$ & Global knock-out & & Reduced total hepatic triglycerides level & Adamovich et al. (2014) \\
\hline Cry $1 /$ Cry 2 & Global knock-out & $\begin{array}{l}\text { Increased plasma glucose and reduced } \\
\text { glucose tolerance }\end{array}$ & & Lamia et al. (2011) \\
\hline \multirow[t]{2}{*}{$\operatorname{Rev}-\operatorname{erb} \alpha$} & Global knock-out & Mild hyperglycemia & Increased adiposity & Delezie et al. (2012) \\
\hline & Global knock-out & & $\begin{array}{l}\text { Decreased expression of } \\
\text { cholesterol-7a-hydroxylase } \\
\text { (CYP7A1) }\end{array}$ & $\begin{array}{l}\text { Duez et al. (2008); } \\
\text { Le Martelot et al. (2009) }\end{array}$ \\
\hline
\end{tabular}

milder impairment in glucose tolerance was detected in mice lacking either Cry1 (Cry $1^{-/-}$) or Cry2 (Cry2 $2^{-/-}$) (Barclay et al., 2013; Lamia et al., 2011). Moreover, mice overexpressing mutated CRY1 show symptoms of diabetes mellitus, while overexpression of Cry1 specifically in the liver of diabetic $d b / d b$ mice improves their insulin sensitivity (Okano et al., 2009; Zhang et al., 2010). In hepatocytes, CRY1 has been found to form a complex with the glucocorticoid receptor and subsequently repress the transcription of phosphoenolpyruvate kinase (PEPCK), the enzyme that catalyses the ratecontrolling step of gluconeogenesis (Lamia et al., 2011).

REV-ERB $\alpha$ (also named NR1D1) was initially discovered as a nuclear receptor regulating lipid metabolism and adipocyte differentiation (Fontaine et al., 2003). The modulatory role of REV$\mathrm{ERB} \alpha$ in the molecular clock machinery and its interactions with metabolic transcription factors, such as peroxisome proliferatoractivated receptors (PPAR), has established its functional position at the interface between metabolic processes and the circadian clocks (Preitner et al., 2002; Teboul et al., 2008). REV-ERB $\alpha$ may regulate glucose homeostasis through its transcriptional control of the expression of gluconeogenic enzymes in cultured hepatocytes, including glucose-6-phosphatase and PEPCK (Yin et al., 2007). Mice lacking Rev-erb $\alpha$ display increased adiposity and mild hyperglycemia over the $24 \mathrm{~h}$ cycle, but without insulin resistance (Delezie et al., 2012). In vitro down-regulation of Rev-erb $\alpha$ by RNA interference treatment in pancreatic $\beta$ cells or insulinoma cells impairs glucose-induced insulin secretion (Vieira et al., 2012). Rev-erb $\alpha$ is highly expressed in oxidative skeletal muscles where it controls muscle mitochondrial content and oxidative function (Woldt et al., 2013). A deficiency in Rev-erb $\alpha$ expression in the muscle may impact glucose homeostasis, because after a meal most of the circulating glucose is taken up by skeletal muscles. Muscle-specific
Rev-erb $\alpha$ KO mice could therefore provide a better insight in the regulation of glucose metabolism by the muscle clock. An overview of the metabolic disturbances associated with glucose metabolism in the different clock gene $\mathrm{KO}$ and mutant mice is summarized in Table 1.

\section{Circadian regulation of lipid homeostasis in nocturnal mammals}

Like glucose, lipid metabolism also shows clear daily rhythms in order to fulfill time of the day-dependent energy requirements in association with sleep/wake and fasting/feeding cycles. In this section, we summarize what is known about the daily regulation of lipid metabolism by circadian clocks.

\subsection{Daily rhythms of lipid metabolism}

Plasma lipid concentrations as well as their biosynthesis show a clear diurnal rhythmicity. Lipids being hydrophobic molecules cannot circulate readily in the aqueous blood. As a consequence, transportation of lipids via the general circulation depends on their association with hydrophilic molecules, called apolipoproteins. Lipid molecules, such as triglycerides (TG) and cholesterol, are transported with the help of these apolipoproteins (Challet, 2013; Hussain and Pan, 2009). Experiments in rats and mice suggest that the nocturnal rise in plasma TGs and cholesterol is caused by changes in apoB lipoproteins. Moreover, the intestinal and hepatic expression of the microsomal triglyceride transfer protein (MTP) is rhythmic and in phase with plasma lipids (Pan and Hussain, 2007). Furthermore, circadian oscillations of plasma TGs in fasted animals strengthen evidence of clock mechanisms that control the diurnal 
variations of plasma lipids (Escobar et al., 1998; Fukagawa et al., 1994). Interestingly, diurnal variations of both MTP and plasma lipids are altered when mice are kept in constant lighting conditions (light or dark) or subjected to restricted feeding conditions, indicating additional regulation by light and feeding cues (Pan and Hussain, 2007).

Absorption of lipids takes place rhythmically in the intestine. By exploiting a so-called in situ loop technique and studying isolated enterocytes, Pan and Hussain (2009) reported that the rate of lipid and cholesterol absorption is higher during the active period and lower during the resting period in nocturnal mice. Intestinal epithelial cells exhibit rhythms in clock gene expression that are synchronized by SCN cues and the availability of food. Specifically, clock gene expression in the intestinal epithelial cells may control the rhythmic expression of different proteins involved in lipid absorption, such as MTP, apolipoprotein A IV and nocturnin (Hussain and Pan, 2014). Circadian oscillations of clock genes are not restricted only to the intestine, but can also be found in other regions and cell types of the gastrointestinal tract (Hoogerwerf et al., 2007; Pardini et al., 2005; Sladek et al., 2007).

Regulation of lipid biosynthesis, transport and their breakdown for energy substrate are firmly associated. Diurnal variations of lipid biosynthesis in the liver, intestine and fat tissues have been reported. Expression of genes involved in TG biosynthesis shows circadian rhythmicity (Adamovich et al., 2014; Kohsaka et al., 2007; Kudo et al., 2007; Shostak et al., 2013). For example, sterol regulatory element-binding protein (SREBP)-1c, acetyl co-A carboxylase (ACC), acyl-CoA synthetase (ACSL), fatty acid synthase (FAS) and fatty acid binding protein 4 show diurnal variations in the liver and adipose tissue of mice (Kohsaka et al., 2007; Kudo et al., 2007; Shostak et al., 2013). Recently, Adamovich et al. (2014) reported that wild-type mice fed ad libitum show circadian expression of liver enzymes that participate in TG biosynthesis, including glycerol-3-phosphate acyltransferase (GPAT), 1acylglycerol-3-phosphate acyltransferase (AGPAT), lipin and diacylglycerol acyltransferase (DGAT) (Adamovich et al., 2014). In addition to TG, cholesterol biosynthesis also exhibits diurnal variations in the liver and intestine. Several in vitro and in vivo studies suggest that expression as well as the activity of HMG CoA reductase, a rate limiting enzyme of cholesterol biosynthesis, exhibits a diurnal rhythm (Edwards et al., 1972; Hamprecht et al., 1969; Mayer, 1976; Mortimer et al., 1998; Shapiro and Rodwell, 1969). Like lipid biosynthesis their breakdown and transport also vary in a time-of-day dependent manner. Circadian oscillations of gene expression of enzymes involved in lipolysis and betaoxidation of fatty acids have also been reported. For instance, enzymes such as adipose triglyceride lipase (ATGL), hormonesensitive lipase (HSL), carnitine palmitoyltransferase 1, and medium-chain acyl-CoA dehydrogenase have been shown to display circadian rhythms at the transcription level in different tissues (Bailey et al., 2014). Lipoprotein lipase (LPL) is an enzyme which cleaves circulating TGs and releases free fatty acids (FFA) for their cellular uptake (Gimble and Floyd, 2009). Lpl is intensely expressed in the adipose tissue and skeletal muscle where lipids are stored and utilized, respectively. The activity of LPL displays a diurnal variation with a phase which is opposite between adipose tissue and skeletal muscle in a given species. In nocturnal rats for instance, LPL activity increases during the dark period in adipose tissue (i.e., leading to accelerated fat accumulation), while its activity increases during the light period in the skeletal muscles (i.e., to support increased fat uptake and oxidation) (Tsutsumi et al., 2002). Circulating levels of FFA show an elevation during the light period (i.e., during fasting) and decline during the dark period (i.e., during feeding) in nocturnal rats and mice (Shostak et al., 2013; Stavinoha et al., 2004; Tsutsumi et al., 2002). Abrogation of the daily plasma FFA rhythm in rats with a bilaterally ablated $\mathrm{SCN}$ indicates the involvement of the central clock in daily changes in plasma FFA (Yamamoto et al., 1987).

There is evidence that the SCN uses the autonomic nervous pathways to control the day/night rhythms in lipid metabolism, in a similar way as it controls glucose homeostasis. Neuroanatomical tracing studies revealed that adipose tissue is deeply innervated by sympathetic as well as parasympathetic wiring (Bamshad et al., 1998; Kreier et al., 2002). The activation of sympathetic fibers is associated with enhanced lipolysis, whereas parasympathetic denervation leads to reduction in insulin-mediated uptake of glucose and FFA in adipose tissue. Furthermore, in the absence of parasympathetic input, the activity of HSL increased by $51 \%$ in the denervated adipose tissue. These findings demonstrate that sympathetic input stimulates catabolism, whereas parasympathetic input governs the anabolic function in the white adipose tissues. The presence of both "sympathetic" and "parasympathetic" neurons in the hypothalamus, including the SCN (Kalsbeek et al., 2007), provides clear evidence that the SCN can regulate lipid metabolism in the adipose tissue by exploiting both branches of the autonomic nervous system.

\subsection{Role of clock components in lipid metabolism}

Mutations and KO of clock or clock-controlled genes affects lipid metabolism too. Evidence for the involvement of Clock in lipid homeostasis has come from the metabolic phenotype of Clock mutant mice that show hyperleptinemia, hypertriglyceridemia and elevated serum cholesterol (Turek et al., 2005). Additional experiments suggest that Clock regulates lipid metabolism by affecting lipid uptake, absorption, biosynthesis and breakdown. Clock mutant $\left(\right.$ Clock $\left.^{m t / m t}\right)$ mice that express the dominant-negative protein display high expression of MTP. CLOCK negatively regulates MTP expression by up-regulating small heterodimer partner (SHP) which suppress MTP expression by binding to the Hepatocyte Nuclear Factor $4 \alpha$ (HNF4 $\alpha$ )/liver nuclear receptor homolog 1 (LRH1) at the MTP promoter (Pan et al., 2010). The genes involved in lipid absorption do not show circadian expression in Clock $^{\mathrm{mt} / \mathrm{mt}}$ mice and remain irresponsive to restricted feeding (Pan and Hussain, 2009; Pan et al., 2010). Clock mutant mice also display altered rhythmic expression of genes involved in TG synthesis and lipolysis (Kudo et al., 2007; Shostak et al., 2013; Tsai et al., 2010).

Loss of BMAL1 in mice leads to a disruption of the daily oscillation of plasma TG (Rudic et al., 2004). BMAL1 also regulates adipogenesis, since mice lacking Bmal1 show decreases in adipogenesis and expression of several crucial adipogenic or lipogenic factors, such as PPAR $\gamma$, adipocyte fatty acid-binding protein 2 (aP2), CCAAT/enhancer-binding protein (C/EBP) $\alpha$, SREBP-1a, and FAS. On the other hand, overexpression of BMAL1 in adipocytes stimulates the lipid synthesis process (Shimba et al., 2005). Embryonic fibroblasts from Bmal1 $\mathrm{KO}$ mice fail to differentiate into adipocytes. A recent study of Zhang et al. (2014) suggests that BMAL1 promotes de novo lipogenesis via insulin-mTORC2-AKT (Zhang et al., 2014). Furthermore, adipose tissue isolated from Clock $^{-1-}$ and Bmal1 $^{-1-}$ mice do not show rhythmic oscillations of lipolytic genes, such as $\mathrm{Hsl}$ and $\mathrm{Atgl}$, which suggest a role of CLOCK and BMAL1 in lipolysis (Shostak et al., 2013). Mice deficient in Bmal1 show impairments in fat storage as well as utilization. Bmal1 KO mice display increased levels of circulating FFA, which induces the formation of ectopic fat in the liver and skeletal muscle. At the same time, these mutant mice show high values of their respiratory quotient, suggesting also a role for BMAL1 in the utilization of fat as an energy source (Shimba et al., 2011). A summary of the changes in lipid metabolism in the different clock gene $\mathrm{KO}$ and mutant mice is presented in Table 1. 
Altered lipid metabolism has also been reported in Per and Cry deficient mice. Plasma TG levels in mice lacking Per1 and/or Per 2 are reduced (Adamovich et al., 2014; Grimaldi et al., 2010). The study in Per2 KO mice revealed that PER2 exerts its inhibitory action on PPAR $\gamma$, a master regulator of lipid metabolism, by blocking its ability to recruit promoters (Grimaldi et al., 2010). Deficiency in Cry leads to increased susceptibility to diet-induced obesity. Cry $1 / 2^{-/-}$ mice challenged with high-fat diet become obese more rapidly as compared to wild-type animals and they show an up-regulation of white adipose tissue genes associated with lipid uptake and lipogenesis, such as Fas, Lpl, Acc1, Acsl4, Dgat1 and -2, and leptin (Barclay et al., 2013).

Mice lacking Rev-erb $\alpha$, the main repressor of Bmal1, display impaired lipid and bile acid metabolism as well as adipogenesis (Fontaine et al., 2003; Le Martelot et al., 2009). PPAR $\gamma$ is a prime regulator of lipid metabolism and adipocyte differentiation that also modulates the transcription of Rev-erb $\alpha$ (Fontaine et al., 2003). The regulatory function of REV-ERB $\alpha$ is controlled by the nuclear receptor co-repressor 1 (NCoR1) that activates a subunit of histone deacetylase 3 (HDAC3) to mediate transcriptional repression of target genes such as Bmal1. Genetic disruption of the NCoR1HDAC3 association leads to a significant increase in serum ketone bodies and FFA levels, as well as a marked alteration in the daily variation of several hepatic genes involved in lipid metabolism (Alenghat et al., 2008). HDAC3 recruitment to the genome shows a circadian variation in the mouse liver with high and low efficiencies during the light and dark periods, respectively. REV-ERB $\alpha$ and NCoR1 recruitments being in phase with HDAC3 recruitment, a low concentration of REV-ERB $\alpha$ decreases the association of HDAC3 with liver metabolic genes in the dark phase, which favors lipid biosynthesis and storage. On the other hand, in the light phase, high levels of REV-ERB $\alpha$ increase the association of HDAC3 with liver metabolic genes, therefore reducing lipid biosynthesis. Deletion of either Rev-erb $\alpha$ or HDAC3 in the mouse liver causes hypertriglyceridemia and liver steatosis (Feng et al., 2011).

The deletion of Rev-erb $\alpha$ also leads to increased adiposity with chow feeding, in the absence of significant hyperphagia or hypoactivity. Rev-erb $\alpha^{-1-}$ mice show increased susceptibility to dietinduced obesity and alterations of rhythmic metabolic gene expression associated with lipid metabolism. When these KO mice are challenged with fasting for $24 \mathrm{~h}$, they preferentially utilize lipid over glucose (Delezie et al., 2012). Genetic loss-of-function and gain-of-function experiments provided evidence that REV-ERB $\alpha$ is involved in the circadian modulation of SREBP activity, and hence the daily expression of SREBP target genes involved in cholesterol and lipid metabolism (Le Martelot et al., 2009). In addition, REV$\mathrm{ERB} \alpha$ also participates in the rhythmic expression of cholesterol-7ahydroxylase (CYP7A1), a rate-limiting enzyme that converts cholesterol to bile acids (Duez et al., 2008; Le Martelot et al., 2009).

Lipid homeostasis is also perturbed by disruption of clockcontrolled genes downstream of the core clock machinery. The ablation of nocturnin in mice leads to a lean phenotype with low body weight and reduced visceral fat, even when the animals are challenged with high-fat diet (Green et al., 2007). Nocturnin mutant mice $\left(\mathrm{Noc}^{-1-}\right)$ absorb less TG after an oral gavage with olive oil (Douris et al., 2011). Gene expression analyses suggest disturbed lipid metabolism and uptake in the $\mathrm{NoC}^{-1-}$ mice. Genes involved in TG synthesis and storage and chylomicron formation show altered expression, and large cytoplasmic lipid droplets accumulate in the apical domains of enterocytes. Likewise, deficiency of the estrogenrelated receptor- $\alpha($ ERR- $\alpha)$ also results in resistance to high-fat-diet induced obesity and metabolic dysregulation with reduced peripheral fat deposit (Dufour et al., 2011). Finally, also deletion of p $75^{\mathrm{NTR}}$ alters the rhythmic oscillation of genes participating in lipid metabolism (Baeza-Raja et al., 2013).

\section{Circadian regulation of metabolic homeostasis in diurnal mammals}

Circadian control of metabolic homeostasis has been extensively investigated in laboratory nocturnal rodents, such as rats and mice. In this section we summarize what is known about the circadian regulation of hormone rhythms and glucose and lipid metabolism in diurnal rodents as well as in humans.

\subsection{Hormonal rhythms in diurnal mammals}

In both nocturnal and diurnal rodents, plasma concentrations of leptin show a post-prandial elevation and reach their zenith around the middle of the feeding period and decline thereafter (Cuesta et al., 2009; Kalra et al., 2003) (Fig.3). Circadian variations of circulating leptin have been also reported in humans, but unlike rodents, the peak of leptin secretion occurs at night (i.e., during the fasting/sleep period), favoring a decreased appetite state. Meal timing also impacts the daily rhythm of leptin secretion in humans, which is in line with the post-prandial elevations observed in animals (Schoeller et al., 1997; Xu et al., 1999). Post-prandial elevations in plasma leptin are a salient signal to the hypothalamus that peripheral energy demand has been met or is going to be met. In humans an elevation of circulating ghrelin levels is found at night during sleep, while this level declines before awakening in the morning (Cummings et al., 2001). Hence, the midnight peak of anorectic leptin secretion could counterbalance the stimulatory effect of nocturnal ghrelin release. Plasma ghrelin rhythms in diurnal rodents have not been reported yet.

In diurnal and nocturnal species, the peak of plasma GC (corticosterone in lab and Grass rats, and cortisol in humans) is phaselocked with the activity onset, which occurs at dawn and dusk in diurnal and nocturnal mammals, respectively (Fig. 3). Vasopressin release from the SCN in the PVN region is high during the light period in both diurnal and nocturnal animals. It is noteworthy, however, that PVN neurons in diurnal and nocturnal rodents respond differently to vasopressin administration. Indeed, vasopressin administered in the PVN of the diurnal Grass rat (Arvicanthis) has a stimulatory effect on the release of plasma corticosterone, while the same treatment in nocturnal rats lowers plasma corticosterone levels (Kalsbeek et al., 2008b). These findings highlight that the 12 -h reversal of GC and other rhythms between diurnal and nocturnal mammals may be due to an opposite responsiveness of PVN and other SCN target areas to signals coming from the SCN. In humans, the cortisol rhythm is affected by perturbations of the sleep-wake cycle (e.g. jet lag, shift work and sleep deprivation), as well as by acute and chronic stress (reviewed in Tsang et al., 2013). Moreover, bright light in the morning, but not in the afternoon, nor at night, triggers a significant increase in plasma cortisol (Leproult et al., 2001; Scheer and Buijs, 1999).

One exception to the common scheme of 12-h reversal of hormonal rhythms between diurnal and nocturnal species is pineal melatonin. Unlike the GC rhythm which is oppositely phased between nocturnal and diurnal animals, melatonin is always secreted during the astronomical dark period that corresponds to the active phase in nocturnal, but resting phase in diurnal species (Pevet and Challet, 2011) (Fig.3). Regarding the SCN control of the daily melatonin rhythm in diurnal species, we suggest that it is close to the one described in nocturnal rats, based on the fact that the phase-relationship between the phase of SCN activity (clockwork and firing rate) and melatonin release is similar in nocturnal and diurnal species (i.e., SCN neuronal activity is high when melatonin release is low during daytime, and vice versa at night). Because of its sedative effects in humans and its efficiency to treat some sleep disorders, melatonin has been considered as a "sleep" hormone, but 

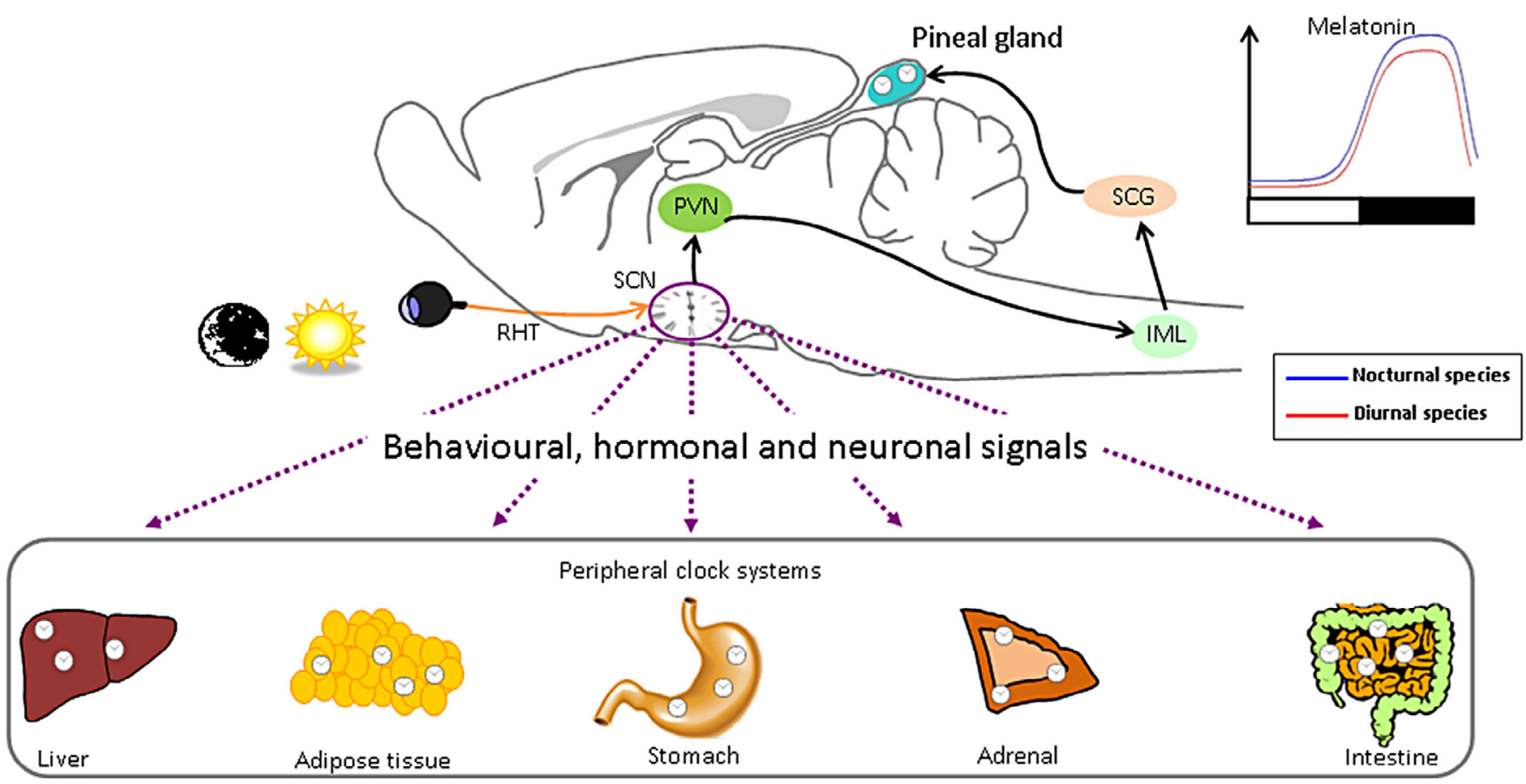

Glucose
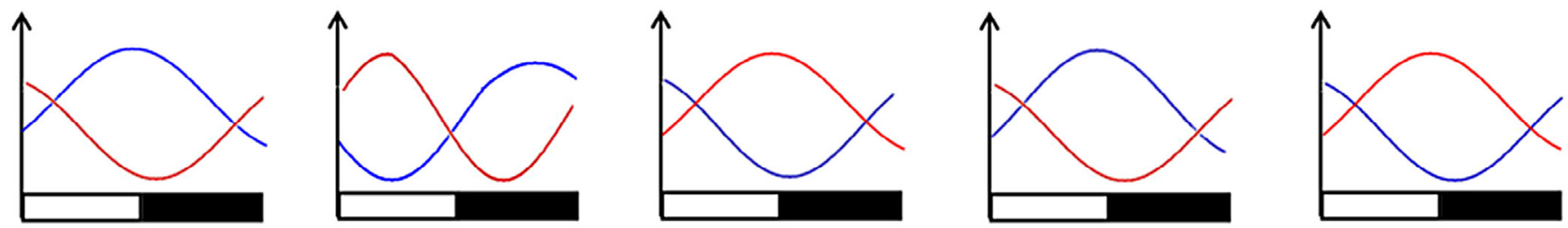

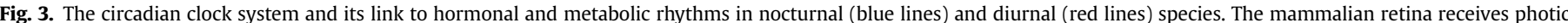

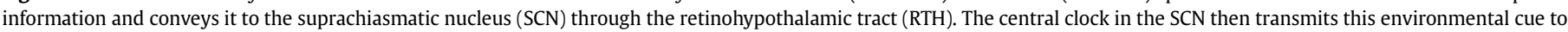

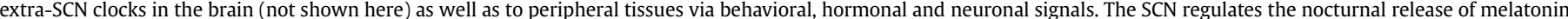

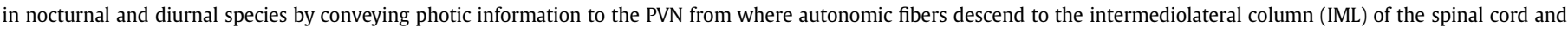

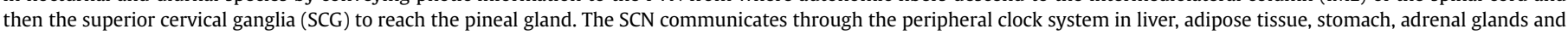

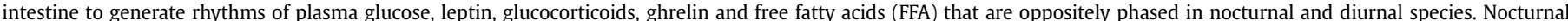

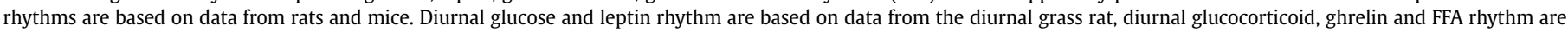
based on human data.

this name/function is of course only correct for diurnal species (i.e., at physiological doses, melatonin does not promote sleep in nocturnal species as they are awake). As mentioned earlier, bright light during nighttime inhibits secretion of pineal melatonin. This observation has been confirmed in all species studied so far, including in humans (Redlin, 2001).

\subsection{Circadian regulation of glucose metabolism in diurnal mammals}

Like in nocturnal mice and rats, plasma glucose concentrations show a day-night rhythm in diurnal rodents as well as in humans, but this rhythm is oppositely phased between nocturnal and diurnal animals (Fig. 3). Daily rhythmicity of plasma glucose in the diurnal Sudanian grass rat (Arvicanthis ansorgei) shows an acrophase before activity onset (Cuesta et al., 2009). Levels of plasma glucose in human subjects also show a daily rhythm, with a peak before the beginning of wake period, the so-called dawn phenomenon (Arslanian et al., 1990; Bolli et al., 1984). In diurnal horse and sheep, however, plasma glucose concentrations peak around mid-night and at dusk, respectively (Piccione et al., 2005). Understanding the mechanisms that underlie these inter-species differences need further investigation. Studies in human subjects indicate that glucose tolerance and insulin sensitivity also vary throughout the day. Both glucose tolerance and insulin sensitivity are more efficient in the morning compared to the evening (Van Cauter et al., 1997).

\subsection{Circadian regulation of lipid metabolism in diurnal mammals}

Daily variations of plasma lipids are robust and in anti-phase, between nocturnal rodents and diurnal humans (Fig. 3). Human subjects show higher levels of plasma FFA at night due to enhanced lipolytic activity and this variation persists during fasting (Carroll and Nestel, 1973; Gibson et al., 1975; Schlierf and Dorow, 1973). When minimizing the indirect effects of calorie intake and sleep, by maintaining human subjects in constant dim light, feeding them with hourly isocaloric meals and keeping them awake for 40 hours, Dallmann et al. (2012) reported a maintenance of rhythmic plasma FFA levels. In other diurnal animals, like goat and horse, FFA levels are decreased at night and rise in early morning, whereas this rhythm eventually disappears in constant darkness (AlilaJohansson et al., 2004; Orme et al., 1994). 


\section{Circadian desynchronization}

\subsection{Deleterious effects of circadian desynchronization on metabolic health}

Being diurnal, human daytime activities usually include feeding, work and exercise, while sleep normally takes place during the night-time. However, the structure and functioning of today's society compel us to loosen this circadian synchrony by increasing night activities, such as shift work and night snacking, by delayed or disturbed sleep, or by traveling frequently across different time zones. It is likely that an appropriate synchrony between the timing of our internal clocks and the daily activities helps to maintain metabolic homeostasis. Indeed, increasing evidence from both epidemiological studies and laboratory experiments indicates that forced circadian misalignment disrupts metabolic rhythms and may thus lead to metabolic abnormalities, such as obesity, type 2 diabetes mellitus, and cardiovascular diseases (Salgado-Delgado et al., 2013; Scheer et al., 2009; Sookoian et al., 2007). Leproult et al. (2014) showed the adverse effects of circadian misalignment on glucose metabolism and cardiovascular health in healthy human subjects. Animal studies support this observation as forced feeding and activity during the usual sleep phase impaired metabolic homeostasis and led to increased body weight gain in rodents (Arble et al., 2009; Salgado-Delgado et al., 2013). In humans, the night-eating syndrome is characterized by the voluntary or uncontrolled food consumption during the night, which is closely related with sleep-related eating disorders. Noteworthy, nighteating syndrome is associated with obesity, as well as hormonal and neurochemical disturbances (Gallant et al., 2012; Zawilska et al., 2010). Moreover, medical students who live a nocturnal life and consume a majority of their food at night display an attenuation of their night-time plasma melatonin and leptin peaks and an impaired response of insulin to glucose, changes that are consistent with those in patients with night-eating syndrome (Qin et al., 2003). Furthermore, dysregulation of the circadian clock in adipose tissue and/or misalignment of meal time may lead to disrupted expression patterns of enzymes involved in lipid metabolism and perturb fatty acid homeostasis (Maury et al., 2010).

Besides experimental studies investigating the role of circadian desynchronization and its impact on energy metabolism, genetic variations in circadian genes in humans are also associated with effects on glucose and lipid homeostasis. Clock and Bmal1 gene polymorphisms in humans suggest that genetic variation in these genes may play a role in the development of obesity and type 2 diabetes (Scott et al., 2008; Sookoian et al., 2008; Woon et al., 2007). Single-nucleotide polymorphisms (SNPs) in CLOCK are correlated with elevated plasma ghrelin levels, reduced sleep duration and increased energy intake (Garaulet et al., 2010, 2011). Furthermore, carriers of CLOCK SNPs display lower plasma glucose concentrations and improved insulin sensitivity when they eat a diet rich in mono-unsaturated fatty acids (Garaulet et al., 2009; Garcia-Rios et al., 2014). Polymorphisms in the Per2 and Npas2 genes have been associated with high fasting plasma glucose levels (Englund et al., 2009). Moreover, SNPs in loci in or near the CRY2 gene have been associated with high fasting glucose levels in nondiabetic participants (Dupuis et al., 2010; Liu et al., 2011). Rev-erb $\alpha$ gene polymorphisms in obese subjects are correlated with adiposity, but not plasma glucose and plasma insulin levels (Goumidi et al., 2013). Finally, genome-wide association studies indicate that polymorphisms in the melatonin receptors MTNR1A and MTNR1B, which are expressed not only in the SCN but also in many peripheral tissues, are linked to increased plasma glucose levels and risk of type 2 diabetes (Bouatia-Naji et al., 2009; Li et al., 2011; Lyssenko et al., 2009; Prokopenko et al., 2009). Altered oscillations of mRNAs encoding circadian regulatory proteins within human subcutaneous adipose tissue are correlated with increased risk of obesity (Wu et al., 2009). Specifically, CLOCK gene polymorphisms are associated with metabolic syndrome, whereas $\mathrm{REV}-\mathrm{ERB} \alpha$ polymorphisms seem to modulate adiposity in both adult and young people (Garaulet and Madrid, 2009; Goumidi et al., 2013). Although there is no complete mechanistic explanation yet for these observations, they clearly point to adverse effects of a misalignment between circadian rhythmicity and energy homeostasis.

\section{Acknowledgements}

Our studies were supported by a doctoral fellowship from the "Neurotime" Erasmus Mundus program (P.K.J.) and grants from Centre National de la Recherche Scientifique, University of Strasbourg (E.C.) and the University of Amsterdam (A.K.).

\section{References}

Abe, M., Herzog, E.D., Yamazaki, S., Straume, M., Tei, H., Sakaki, Y., et al., 2002 Circadian rhythms in isolated brain regions. J. Neurosci 22, 350-356.

Abraham, U., Prior, J.L., Granados-Fuentes, D., Piwnica-Worms, D.R., Herzog, E.D, 2005. Independent circadian oscillations of Period1 in specific brain areas in vivo and in vitro. J. Neurosci 25, 8620-8626.

Abrahamson, E.E., Leak, R.K., Moore, R.Y., 2001. The suprachiasmatic nucleus projects to posterior hypothalamic arousal systems. Neuroreport 12, 435-440.

Adamovich, Y., Rousso-Noori, L., Zwighaft, Z., Neufeld-Cohen, A., Golik, M., KrautCohen, J., et al., 2014. Circadian clocks and feeding time regulate the oscillations and levels of hepatic triglycerides. Cell Metab 19, 319-330.

Alam, M.N., Kumar, S., Bashir, T., Suntsova, N., Methippara, M.M., Szymusiak, R. et al., 2005. GABA-mediated control of hypocretin - but not melanin -concentrating hormone-immunoreactive neurones during sleep in rats. J. Physiol 563, 569-582.

Alberts, P., Johansson, B.G., McArthur, R.A., 2006. Characterization of energy expenditure in rodents by indirect calorimetry. Curr Protoc Neurosci. Chapter 9 Unit9 23D.

Alenghat, T., Meyers, K., Mullican, S.E., Leitner, K., Adeniji-Adele, A., Avila, J., et al., 2008. Nuclear receptor corepressor and histone deacetylase 3 govern circadian metabolic physiology. Nature 456, 997-1000.

Alila-Johansson, A., Eriksson, L., Soveri, T., Laakso, M.L., 2004. Daily and annual variations of free fatty acid, glycerol and leptin plasma concentrations in goats (Capra hircus) under different photoperiods. Comp. Biochem. Physiol. A. Mol Integr. Physiol 138, 119-131.

Arble, D.M., Bass, J., Laposky, A.D., Vitaterna, M.H., Turek, F.W., 2009. Circadian timing of food intake contributes to weight gain. Obesity (Silver Spring) 17, 2100-2102.

Arslanian, S., Ohki, Y., Becker, D.J., Drash, A.L., 1990. Demonstration of a dawn phenomenon in normal adolescents. Horm. Res 34, 27-32.

Aschoff, J., 1965. Circadian rhythms in man. Science 148, 1427-1432.

Aschoff, J., von Goetz, C., Wildgruber, C., Wever, R.A., 1986. Meal timing in humans during isolation without time cues. J. Biol. Rhythms 1, 151-162.

Asher, G., Gatfield, D., Stratmann, M., Reinke, H., Dibner, C., Kreppel, F., et al., 2008 SIRT1 regulates circadian clock gene expression through PER2 deacetylation. Cell 134, 317-328.

Baeza-Raja, B., Eckel-Mahan, K., Zhang, L., Vagena, E., Tsigelny, I.F., Sassone-Corsi, P. et al., 2013. p75 neurotrophin receptor is a clock gene that regulates oscillatory components of circadian and metabolic networks. J. Neurosci 33, 10221-10234.

Bailey, S.M., Udoh, U.S., Young, M.E., 2014. Circadian regulation of metabolism. J. Endocrinol 222, R75-R96.

Balsalobre, A., Damiola, F., Schibler, U., 1998. A serum shock induces circadian gene expression in mammalian tissue culture cells. Cell 93, 929-937.

Balsalobre, A., Brown, S.A., Marcacci, L., Tronche, F., Kellendonk, C., Reichardt, H.M. et al., 2000. Resetting of circadian time in peripheral tissues by glucocorticoid signaling. Science 289, 2344-2347.

Bamshad, M., Aoki, V.T., Adkison, M.G., Warren, W.S., Bartness, T.J., 1998. Central nervous system origins of the sympathetic nervous system outflow to white adipose tissue. Am. J. Physiol 275, R291-R299.

Barclay, J.L., Shostak, A., Leliavski, A., Tsang, A.H., Johren, O., Muller-Fielitz, H., et al., 2013. High-fat diet-induced hyperinsulinemia and tissue-specific insulin resistance in Cry-deficient mice. Am. J. Physiol. Endocrinol. Metab 304, E1053-E1063.

Bodosi, B., Gardi, J., Hajdu, I., Szentirmai, E., Obal Jr., F., Krueger, J.M., 2004. Rhythms of ghrelin, leptin, and sleep in rats: effects of the normal diurnal cycle, restricted feeding, and sleep deprivation. Am. J. Physiol. Regul. Integr. Comp. Physiol 287, R1071-R1079.

Bolli, G.B., De Feo, P., De Cosmo, S., Perriello, G., Ventura, M.M., Calcinaro, F., et al., 1984. Demonstration of a dawn phenomenon in normal human volunteers. Diabetes 33, 1150-1153. 
Bouatia-Naji, N., Bonnefond, A., Cavalcanti-Proenca, C., Sparso, T., Holmkvist, J. Marchand, M., et al., 2009. A variant near MTNR1B is associated with increased fasting plasma glucose levels and type 2 diabetes risk. Nat. Genet 41, 89-94.

Bray, M.S., Tsai, J.Y., Villegas-Montoya, C., Boland, B.B., Blasier, Z., Egbejimi, O., et al., 2010. Time-of-day-dependent dietary fat consumption influences multiple cardiometabolic syndrome parameters in mice. Int. J. Obes. (Lond.) 34 1589-1598.

Bray, M.S., Ratcliffe, W.F., Grenett, M.H., Brewer, R.A., Gamble, K.L., Young, M.E. 2013. Quantitative analysis of light-phase restricted feeding reveals metabolic dyssynchrony in mice. Int. J. Obes. (Lond.) 37.

Bugge, A., Feng, D., Everett, L.J., Briggs, E.R., Mullican, S.E., Wang, F., et al., 2012. Reverb $\alpha$ and Rev-erb $\beta$ coordinately protect the circadian clock and normal metabolic function. Genes Dev 26, 657-667.

Buijs, R.M., Kalsbeek, A., 2001. Hypothalamic integration of central and peripheral clocks. Nat. Rev. Neurosci 2, 521-526.

Buijs, R.M., Wortel, J., Van Heerikhuize, J.J., Feenstra, M.G., Ter Horst, G.J., Romijn, H.J., et al., 1999. Anatomical and functional demonstration of a multisynaptic suprachiasmatic nucleus adrenal (cortex) pathway. Eur. J. Neurosci 11 1535-1544.

Buijs, R.M., van Eden, C.G., Goncharuk, V.D., Kalsbeek, A., 2003. The biological clock tunes the organs of the body: timing by hormones and the autonomic nervous system. J. Endocrinol 177, 17-26.

Cailotto, C., La Fleur, S.E., Van Heijningen, C., Wortel, J., Kalsbeek, A., Feenstra, M. et al., 2005. The suprachiasmatic nucleus controls the daily variation of plasm glucose via the autonomic output to the liver: are the clock genes involved? Eur: J. Neurosci 22, 2531-2540.

Carroll, K.F., Nestel, P.J., 1973. Diurnal variation in glucose tolerance and in insulin secretion in man. Diabetes 22, 333-348.

Carroll, T.B., Findling, J.W., 2010. The diagnosis of Cushing's syndrome. Rev. Endocr. Metab. Disord 11, 147-153.

Challet, E., 2007. Minireview: entrainment of the suprachiasmatic clockwork in diurnal and nocturnal mammals. Endocrinology 148, 5648-5655.

Challet, E., 2013. Circadian clocks, food intake, and metabolism. Prog. Mol. Biol. Transl. Sci 119, 105-135.

Challet, E., Malan, A., Turek, F.W., Van Reeth, O., 2004. Daily variations of blood glucose, acid-base state and PCO2 in rats: effect of light exposure. Neurosci. Lett $355,131-135$.

Crumbley, C., Burris, T.P., 2011. Direct regulation of CLOCK expression by REV-ERB PLOS ONE 6 e17290.

Cuesta, M., Clesse, D., Pevet, P., Challet, E., 2009. From daily behavior to hormonal and neurotransmitters rhythms: comparison between diurnal and nocturnal rat species. Horm. Behav 55, 338-347.

Cummings, D.E., Purnell, J.Q., Frayo, R.S., Schmidova, K., Wisse, B.E., Weigle, D.S. 2001. A preprandial rise in plasma ghrelin levels suggests a role in meal initiation in humans. Diabetes 50, 1714-1719.

Daan, S., Honma, S., Honma, K., 2013. Body temperature predicts the direction of internal desynchronization in humans isolated from time cues. J. Biol. Rhythms 28, 403-411.

Dallmann, R., Touma, C., Palme, R., Albrecht, U., Steinlechner, S., 2006. Impaired daily glucocorticoid rhythm in Per1 (Brd) mice. J. Comp. Physiol. A. Neuroethol. Sens. Neural Behav, Physiol 192, 769-775.

Dallmann, R., Viola, A.U., Tarokh, L., Cajochen, C., Brown, S.A., 2012. The human circadian metabolome. Proc. Natl. Acad. Sci. USA 109, 2625-2629.

Damiola, F., Le Minh, N., Preitner, N., Kornmann, B., Fleury-Olela, F., Schibler, U., 2000. Restricted feeding uncouples circadian oscillators in peripheral tissues from the central pacemaker in the suprachiasmatic nucleus. Genes Dev 14 $2950-2961$.

Delezie, J., Dumont, S., Dardente, H., Oudart, H., Grechez-Cassiau, A., Klosen, P., et al., 2012. The nuclear receptor REV-ERB $\alpha$ is required for the daily balance of carbohydrate and lipid metabolism. FASEB J. 26, 3321-3335.

Deurveilher, S., Semba, K., 2005. Indirect projections from the suprachiasmatic nucleus to major arousal-promoting cell groups in rat: implications for the circadian control of behavioural state. Neuroscience 130, 165-183.

Dibner, C., Schibler, U., Albrecht, U., 2010. The mammalian circadian timing system: organization and coordination of central and peripheral clocks. Annu. Rev. Physiol 72, 517-549.

Doi, R., Oishi, K., Ishida, N., 2010. CLOCK regulates circadian rhythms of hepatic glycogen synthesis through transcriptional activation of Gys2. J. Biol. Chem 285, 22114-22121.

Douris, N., Kojima, S., Pan, X., Lerch-Gaggl, A.F., Duong, S.Q., Hussain, M.M., et al., 2011. Nocturnin regulates circadian trafficking of dietary lipid in intestinal enterocytes. Curr. Biol 21, 1347-1355.

Duez, H., van der Veen, J.N., Duhem, C., Pourcet, B., Touvier, T., Fontaine, C., et al, 2008. Regulation of bile acid synthesis by the nuclear receptor Rev-erbalpha. Gastroenterology 135, 689-698.

Dufour, C.R. Levasseur, M.P., Pham, N.H., Eichner, L.J., Wilson, B.J., CharestMarcotte, A., et al., 2011. Genomic convergence among ERRalpha, PROX1, and BMAL1 in the control of metabolic clock outputs. PLoS Genet 7 e1002143.

Dupuis, J., Langenberg, C., Prokopenko, I., Saxena, R., Soranzo, N., Jackson, A.U., et al. 2010. New genetic loci implicated in fasting glucose homeostasis and thei impact on type 2 diabetes risk. Nat. Genet 42, 105-116.

Edwards, P.A., Muroya, H., Gould, R.G., 1972. In vivo demonstration of the circadian rhythm of cholesterol biosynthesis in the liver and intestine of the rat. J. Lipid Res 13, 396-401.

Englund, A., Kovanen, L., Saarikoski, S.T., Haukka, J., Reunanen, A., Aromaa, A., et al.
2009. NPAS2 and PER2 are linked to risk factors of the metabolic syndrome. J. Circadian Rhythms 7, 5.

Escobar, C., Diaz-Munoz, M., Encinas, F., Aguilar-Roblero, R., 1998. Persistence of metabolic rhythmicity during fasting and its entrainment by restricted feeding schedules in rats. Am. J. Physiol 274, R1309-R1316.

Feillet, C.A., Ripperger, J.A., Magnone, M.C., Dulloo, A., Albrecht, U., Challet, E., 2006. Lack of food anticipation in Per2 mutant mice. Curr. Biol 16, 2016-2022.

Feng, D., Liu, T., Sun, Z., Bugge, A., Mullican, S.E., Alenghat, T., et al., 2011. A circadian rhythm orchestrated by histone deacetylase 3 controls hepatic lipid metabolism. Science 331, 1315-1319.

Fontaine, C., Dubois, G., Duguay, Y., Helledie, T., Vu-Dac, N., Gervois, P., et al., 2003. The orphan nuclear receptor Rev-Erbalpha is a peroxisome proliferatoractivated receptor (PPAR) gamma target gene and promotes PPARgammainduced adipocyte differentiation. J. Biol. Chem 278, 37672-37680.

Fujii, T., Inoue, S., Nagai, K., Nakagawa, H., 1989. Involvement of adrenergic mechanism in hyperglycemia due to SCN stimulation. Horm. Metab. Res 21, 643-645.

Fukagawa, K., Gou, H.M., Wolf, R., Tso, P., 1994. Circadian rhythm of serum and lymph apolipoprotein AIV in ad libitum-fed and fasted rats. Am. J. Physiol 267, R1385-R1390.

Gallant, A.R., Lundgren, J., Drapeau, V., 2012. The night-eating syndrome and obesity. Obes. Rev 13, 528-536.

Garaulet, M., Madrid, J.A., 2009. Chronobiology, genetics and metabolic syndrome. Curr. Opin. Lipidol 20, 127-134.

Garaulet, M., Lee, Y.C. Shen, J., Parnell, L.D., Arnett, D.K., Tsai, M.Y., et al., 2009. CLOCK genetic variation and metabolic syndrome risk: modulation by monounsaturated fatty acids. Am. J. Clin. Nutr 90, 1466-1475.

Garaulet, M., Lee, Y.C., Shen, J., Parnell, L.D., Arnett, D.K., Tsai, M.Y., et al., 2010. Genetic variants in human CLOCK associate with total energy intake and cytokine sleep factors in overweight subjects (GOLDN population). Eur. J. Hum, Genet 18, 364-369.

Garaulet, M., Sanchez-Moreno, C., Smith, C.E., Lee, Y.C., Nicolas, F., Ordovas, J.M., 2011. Ghrelin, sleep reduction and evening preference: relationships to CLOCK 3111 T/C SNP and weight loss. PLoS ONE 6 e17435.

Garcia-Rios, A., Gomez-Delgado, F.J., Garaulet, M., Alcala-Diaz, J.F., Delgado-Lista, F.J., Marin, C., et al., 2014. Beneficial effect of CLOCK gene polymorphism rs 1801260 in combination with low-fat diet on insulin metabolism in the patients with metabolic syndrome. Chronobiol. Int 31, 401-408.

Gibson, T., Stimmler, L., Jarrett, R.J., Rutland, P., Shiu, M., 1975. Diurnal variation in the effects of insulin on blood glucose, plasma non-esterified fatty acids and growth hormone. Diabetologia 11, 83-88.

Gimble, J.M., Floyd, Z.E., 2009. Fat circadian biology. J. Appl. Physiol. (1985) 107, 1629-1637.

Goumidi, L., Grechez, A., Dumont, J., Cottel, D., Kafatos, A., Moreno, L.A., et al., 2013. Impact of REV-ERB alpha gene polymorphisms on obesity phenotypes in adult and adolescent samples. Int. J. Obes. (Lond.) 37, 666-672.

Green, C.B., Douris, N., Kojima, S., Strayer, C.A., Fogerty, J., Lourim, D., et al., 2007. Loss of Nocturnin, a circadian deadenylase, confers resistance to hepatic steatosis and diet-induced obesity. Proc. Natl. Acad. Sci. U.S.A. 104, 9888-9893.

Grimaldi, B., Bellet, M.M., Katada, S., Astarita, G., Hirayama, J., Amin, R.H., et al., 2010. PER2 controls lipid metabolism by direct regulation of PPAR $\gamma$. Cell Metab 12, 509-520.

Grimaldi, D., Silvani, A., Benarroch, E.E., Cortelli, P., 2014. Orexin/hypocretin system and autonomic control: new insights and clinical correlations. Neurology 82, 271-278.

Guilding, C., Piggins, H.D., 2007. Challenging the omnipotence of the suprachiasmatic timekeeper: are circadian oscillators present throughout the mammalian brain? Eur. J. Neurosci 25, 3195-3216.

Guillaumond, F., Dardente, H., Giguere, V., Cermakian, N., 2005. Differential control of Bmal1 circadian transcription by REV-ERB and ROR nuclear receptors. J. Biol. Rhythms 20, 391-403.

Hamprecht, B., Nussler, C., Lynen, F., 1969. Rhythmic changes of hydroxymethylglutaryl coenzyme a reductase activity in livers of fed and fasted rats. FEBS Lett 4, 117-121.

Haraguchi, A., Aoki, N., Ohtsu, T., Ikeda, Y., Tahara, Y., Shibata, S., 2014. Controlling access time to a high-fat diet during the inactive period protects against obesity in mice. Chronobiol. Int 31, 935-944.

Hatori, M., Vollmers, C., Zarrinpar, A., DiTacchio, L., Bushong, E.A., Gill, S., et al., 2012. Time-restricted feeding without reducing caloric intake prevents metabolic diseases in mice fed a high-fat diet. Cell Metab 15, 848-860.

Hoogerwerf, W.A., Hellmich, H.L., Cornelissen, G., Halberg, F., Shahinian, V.B., Bostwick, J., et al., 2007. Clock gene expression in the murine gastrointestinal tract: endogenous rhythmicity and effects of a feeding regimen. Gastroenterology $133,1250-1260$

Hosoya, Y., Sugiura, Y., Okado, N., Loewy, A.D., Kohno, K., 1991. Descending input from the hypothalamic paraventricular nucleus to sympathetic preganglionic neurons in the rat. Exp. Brain Res 85, 10-20.

Hughes, A.T., Piggins, H.D., 2012. Feedback actions of locomotor activity to the circadian clock. Prog. Brain Res 199, 305-336.

Hussain, M.M., Pan, X., 2009. Clock genes, intestinal transport and plasma lipid homeostasis. Trends Endocrinol. Metab 20, 177-185.

Hussain, M.M., Pan, X., 2014. Circadian regulators of intestinal lipid absorption. J. Lipid Res. http://dx.doi.org/10.1194/jlr.R051573.

Ishida, A., Mutoh, T., Ueyama, T., Bando, H., Masubuchi, S., Nakahara, D., et al., 2005 Light activates the adrenal gland: timing of gene expression and glucocorticoid release. Cell Metab 2, 297-307. 
Johnson, C.H., Elliott, J., Foster, R., Honma, K., Kronauer, R., 2004. Fundamental properties of circadian rhythms. In: Dunlap, J.C., Loros, J.J., DeCoursey, P.J. (Eds.), Chronobiology: Biological Timekeeping. Sinauer Associates., Sunderland, MA, pp. 67-105.

Kalra, S.P., Bagnasco, M., Otukonyong, E.E., Dube, M.G., Kalra, P.S., 2003. Rhythmic, reciprocal ghrelin and leptin signaling: new insight in the development of obesity. Regul. Pept 111, 1-11.

Kalsbeek, A., Fliers, E., 2013. Daily regulation of hormone profiles. Handb. Exp. Pharmacol 217, 185-226.

Kalsbeek, A., Strubbe, J.H., 1998. Circadian control of insulin secretion is independent of the temporal distribution of feeding. Physiol. Behav 63, 553-558.

Kalsbeek, A., Fliers, E., Romijn, J.A., La Fleur, S.E., Wortel, J., Bakker, O., et al., 2001. The suprachiasmatic nucleus generates the diurnal changes in plasma leptin levels. Endocrinology 142, 2677-2685.

Kalsbeek, A., La Fleur, S., Van Heijningen, C., Buijs, R.M., 2004. Suprachiasmatic GABAergic inputs to the paraventricular nucleus control plasma glucose concentrations in the rat via sympathetic innervation of the liver. J. Neurosci 24, 7604-7613.

Kalsbeek, A., Palm, I.F., La Fleur, S.E., Scheer, F.A., Perreau-Lenz, S., Ruiter, M., et al., 2006. SCN outputs and the hypothalamic balance of life. J. Biol. Rhythms 21, 458-469.

Kalsbeek, A., Kreier, F., Fliers, E., Sauerwein, H.P., Romijn, J.A., Buijs, R.M., 2007. Minireview: circadian control of metabolism by the suprachiasmatic nuclei. Endocrinology 148, 5635-5639.

Kalsbeek, A., Foppen, E., Schalij, I., Van Heijningen, C., van der Vliet, J., Fliers, E., et al., 2008. Circadian control of the daily plasma glucose rhythm: an interplay of GABA and glutamate. PLoS ONE 3 e3194.

Kalsbeek, A., Verhagen, L.A., Schalij, I., Foppen, E., Saboureau, M., Bothorel, B., et al., 2008. Opposite actions of hypothalamic vasopressin on circadian corticosterone rhythm in nocturnal versus diurnal species. Eur. J. Neurosci 27, 818-827.

Kalsbeek, A., la Fleur, S., Fliers, E., 2014. Circadian control of glucose metabolism. Mol. Metab 3, 372-383.

Kalsbeek, A., Yi, C.X., La Fleur, S.E., Fliers, E., 2010. The hypothalamic clock and its control of glucose homeostasis. Trends Endocrinol. Metab 21, 402-410.

Karasawa, H., Yakabi, S., Wang, L., Tache, Y., 2014. Orexin-1 receptor mediates the increased food and water intake induced by intracerebroventricular injection of the stable somatostatin pan-agonist, ODT8-SST in rats. Neurosci. Lett 576, 88-92.

Kennaway, D.J., Owens, J.A., Voultsios, A., Boden, M.J., Varcoe, T.J., 2007. Metabolic homeostasis in mice with disrupted Clock gene expression in peripheral tissues. Am. J. Physiol. Regul. Integr. Comp. Physiol 293, R1528-R1537.

Kiessling, S., Sollars, P.J., Pickard, G.E., 2014. Light stimulates the mouse adrenal through a retinohypothalamic pathway independent of an effect on the clock in the suprachiasmatic nucleus. PLoS ONE 9 e92959.

Kohsaka, A., Laposky, A.D., Ramsey, K.M., Estrada, C., Joshu, C., Kobayashi, Y., et al., 2007. High-fat diet disrupts behavioral and molecular circadian rhythms in mice. Cell Metab 6, 414-421.

Krauchi, K., Wirz-Justice, A., 2001. Circadian clues to sleep onset mechanisms. Neuropsychopharmacology 25, S92-S96.

Kreier, F., Fliers, E., Voshol, P.J., Van Eden, C.G., Havekes, L.M., Kalsbeek, A., et al., 2002. Selective parasympathetic innervation of subcutaneous and intraabdominal fat - functional implications. J. Clin. Invest 110, 1243-1250.

Kudo, T., Tamagawa, T., Kawashima, M., Mito, N., Shibata, S., 2007. Attenuating effect of clock mutation on triglyceride contents in the ICR mouse liver under a highfat diet. J. Biol. Rhythms 22, 312-323.

la Fleur, S.E., Kalsbeek, A., Wortel, J., Fekkes, M.L., Buijs, R.M., 2001. A daily rhythm in glucose tolerance: a role for the suprachiasmatic nucleus. Diabetes 50, 1237-1243.

la Fleur, S.E., Kalsbeek, A., Wortel, J., van der Vliet, J., Buijs, R.M., 2001. Role for the pineal and melatonin in glucose homeostasis: pinealectomy increases nighttime glucose concentrations. J. Neuroendocrinol 13, 1025-1032.

La Fleur, S.E., Kalsbeek, A., Wortel, J., Buijs, R.M., 1999. A suprachiasmatic nucleus generated rhythm in basal glucose concentrations. J. Neuroendocrinol 11, 643-652.

Lamia, K.A., Storch, K.F., Weitz, C.J., 2008. Physiological significance of a peripheral tissue circadian clock. Proc. Natl. Acad. Sci. U.S.A. 105, 15172-15177.

Lamia, K.A., Sachdeva, U.M., DiTacchio, L., Williams, E.C., Alvarez, J.G., Egan, D.F., et al., 2009. AMPK regulates the circadian clock by cryptochrome phosphorylation and degradation. Science 326, 437-440.

Lamia, K.A., Papp, S.J., Yu, R.T., Barish, G.D., Uhlenhaut, N.H., Jonker, J.W., et al., 2011. Cryptochromes mediate rhythmic repression of the glucocorticoid receptor. Nature 480, 552-556.

Le Martelot, G., Claudel, T., Gatfield, D., Schaad, O., Kornmann, B., Lo Sasso, G., et al., 2009. REV-ERBalpha participates in circadian SREBP signaling and bile acid homeostasis. PLoS Biol 7 e1000181.

Lee, J., Moulik, M., Fang, Z., Saha, P., Zou, F., Xu, Y., et al., 2013. Bmal1 and $\beta$-cell clock are required for adaptation to circadian disruption, and their loss of function leads to oxidative stress-induced $\beta$-cell failure in mice. Mol. Cell. Biol 33, 2327-2338.

Leproult, R., Colecchia, E.F., L'Hermite-Baleriaux, M., Van Cauter, E., 2001. Transition from dim to bright light in the morning induces an immediate elevation of cortisol levels. J. Clin. Endocrinol. Metab 86, 151-157.

Leproult, R., Holmbäck, U., Van Cauter, E., 2014. Circadian misalignment augments markers of insulin resistance and inflammation, independently of sleep loss. Diabetes 63, 1860-1869.
Li, C., Shi, Y., You, L., Wang, L., Chen, Z.J., 2011. Melatonin receptor 1A gene polymorphism associated with polycystic ovary syndrome. Gynecol. Obstet. Invest $72,130-134$.

Lima, F.B., Machado, U.F., Bartol, I., Seraphim, P.M., Sumida, D.H., Moraes, S.M., et al., 1998. Pinealectomy causes glucose intolerance and decreases adipose cell responsiveness to insulin in rats. Am. J. Physiol 275, E934-E941.

Lin, H.V., Accili, D., 2011. Hormonal regulation of hepatic glucose production in health and disease. Cell Metab 14, 9-19.

Liu, C., Li, H., Qi, L., Loos, R.J., Qi, Q., Lu, L., et al., 2011. Variants in GLIS3 and CRY2 are associated with type 2 diabetes and impaired fasting glucose in Chinese Hans. PLoS ONE 6 e21464.

Lucas, R.J., Lall, G.S., Allen, A.E., Brown, T.M., 2012. How rod, cone, and melanopsin photoreceptors come together to enlighten the mammalian circadian clock. Prog. Brain Res 199, 1-18.

Lyssenko, V., Nagorny, C.L., Erdos, M.R., Wierup, N., Jonsson, A., Spegel, P., et al., 2009. Common variant in MTNR1B associated with increased risk of type 2 diabetes and impaired early insulin secretion. Nat. Genet 41, 82-88.

Marcheva, B., Ramsey, K.M., Buhr, E.D., Kobayashi, Y., Su, H., Ko, C.H., et al., 2010. Disruption of the clock components CLOCK and BMAL1 leads to hypoinsulinaemia and diabetes. Nature 466, 627-631.

Maury, E., Ramsey, K.M., Bass, J., 2010. Circadian rhythms and metabolic syndrome: from experimental genetics to human disease. Circ. Res 106, 447-462.

Mayer, D., 1976. The circadian rhythm of synthesis and catabolism of cholesterol. Arch. Toxicol 36, 267-276.

Mohawk, J.A., Green, C.B., Takahashi, J.S., 2012. Central and peripheral circadian clocks in mammals. Annu. Rev. Neurosci 35, 445-462.

Moore, R.Y., Lenn, N.J., 1972. A retinohypothalamic projection in the rat. J. Comp. Neurol 146, 1-14.

Mortimer, B.C., Beveridge, D.J., Phan, C.T., Lutton, C., Redgrave, T.G., 1998. The diurnal rhythms of cholesterol metabolism and plasma clearance of model chylomicrons: comparison of normal and genetically hypercholesterolemic rats (RICO). Comp. Biochem. Physiol. A. Mol Integr. Physiol 120, 671-680.

Nagai, K., Nishio, T., Nakagawa, H., Nakamura, S., Fukuda, Y., 1978. Effect of bilateral lesions of the suprachiasmatic nuclei on the circadian rhythm of food-intake. Brain Res 142, 384-389.

Nagai, K., Fujii, T., Inoue, S., Takamura, Y., Nakagawa, H., 1988. Electrical stimulation of the suprachiasmatic nucleus of the hypothalamus causes hyperglycemia. Horm. Metab. Res 20, 37-39.

Nagai, K., Nagai, N., Sugahara, K., Niijima, A., Nakagawa, H., 1994. Circadian rhythms and energy metabolism with special reference to the suprachiasmatic nucleus. Neurosci. Biobehav. Rev 18, 579-584.

Nakahata, Y., Kaluzova, M., Grimaldi, B., Sahar, S., Hirayama, J., Chen, D., et al., 2008. The NAD+-dependent deacetylase SIRT1 modulates CLOCK-mediated chromatin remodeling and circadian control. Cell 134, 329-340.

Oishi, K., Amagai, N., Shirai, H., Kadota, K., Ohkura, N., Ishida, N., 2005. Genomewide expression analysis reveals 100 adrenal gland-dependent circadian genes in the mouse liver. DNA Res 12, 191-202.

Okano, S., Akashi, M., Hayasaka, K., Nakajima, O., 2009. Unusual circadian locomotor activity and pathophysiology in mutant CRY1 transgenic mice. Neurosci. Lett 451, 246-251.

Orme, C.E., Dunnett, M., Harris, R.C., 1994. Variation in the concentration of long chain free fatty acids in equine plasma over 24 hours. Br. Vet. J. 150, 339-347.

Pan, X., Hussain, M.M., 2007. Diurnal regulation of microsomal triglyceride transfer protein and plasma lipid levels. J. Biol. Chem 282, 24707-24719.

Pan, X., Hussain, M.M., 2009. Clock is important for food and circadian regulation of macronutrient absorption in mice. J. Lipid Res 50, 1800-1813.

Pan, X., Zhang, Y., Wang, L., Hussain, M.M., 2010. Diurnal regulation of MTP and plasma triglyceride by CLOCK is mediated by SHP. Cell Metab 12, 174-186.

Panda, S., Antoch, M.P., Miller, B.H., Su, A.I., Schook, A.B., Straume, M., et al., 2002. Coordinated transcription of key pathways in the mouse by the circadian clock. Cell 109, 307-320.

Pardini, L., Kaeffer, B., Trubuil, A., Bourreille, A., Galmiche, J.P., 2005. Human intestinal circadian clock: expression of clock genes in colonocytes lining the crypt. Chronobiol. Int 22, 951-961.

Patton, D.F., Mistlberger, R.E., 2013. Circadian adaptations to meal timing: neuroendocrine mechanisms. Front. Neurosci 7, 185.

Pevet, P., Challet, E., 2011. Melatonin: both master clock output and internal timegiver in the circadian clocks network. J. Physiol. (Paris) 105, 170-182.

Piccione, G., Caola, G., Refinetti, R., 2005. Temporal relationships of 21 physiological variables in horse and sheep. Comp. Biochem. Physiol. A. Mol Integr. Physiol 142, 389-396.

Picinato, M.C., Haber, E.P., Carpinelli, A.R., Cipolla-Neto, J., 2002. Daily rhythm of glucose-induced insulin secretion by isolated islets from intact and pinealectomized rat. J. Pineal Res 33, 172-177.

Pittendrigh, C., Daan, S., 1976. A functional analysis of circadian pacemekers in nocturnal rodents. J. Comp. Physiol 106, 333-355.

Preitner, N., Damiola, F., Lopez-Molina, L., Zakany, J., Duboule, D., Albrecht, U., et al., 2002. The orphan nuclear receptor REV-ERBalpha controls circadian transcription within the positive limb of the mammalian circadian oscillator. Cell 110, 251-260.

Prokopenko, I., Langenberg, C., Florez, J.C., Saxena, R., Soranzo, N., Thorleifsson, G., et al., 2009. Variants in MTNR1B influence fasting glucose levels. Nat. Genet 41, $77-81$.

Qin, L.Q., Li, J., Wang, Y., Wang, J., Xu, J.Y., Kaneko, T., 2003. The effects of nocturnal life on endocrine circadian patterns in healthy adults. Life Sci 73, 2467-2475. 
Reddy, A.B., Maywood, E.S., Karp, N.A., King, V.M., Inoue, Y., Gonzalez, F.J., et al., 2007. Glucocorticoid signaling synchronizes the liver circadian transcriptome. Hepatology 45, 1478-1488.

Redlin, U., 2001. Neural basis and biological function of masking by light in mammals: suppression of melatonin and locomotor activity. Chronobiol. Int 18 , 737-758.

Reppert, S.M., Weaver, D.R., 2002. Coordination of circadian timing in mammals. Nature 418, 935-941.

Rudic, R.D., McNamara, P., Curtis, A.M., Boston, R.C., Panda, S., Hogenesch, J.B., et al., 2004. BMAL1 and CLOCK, two essential components of the circadian clock, are involved in glucose homeostasis. PLoS Biol 2 e377.

Ruiter, M., La Fleur, S.E., van Heijningen, C., van der Vliet, J., Kalsbeek, A., Buijs, R.M., 2003. The daily rhythm in plasma glucagon concentrations in the rat is modulated by the biological clock and by feeding behavior. Diabetes 52 , 1709-1715.

Sadacca, L.A., Lamia, K.A., deLemos, A.S., Blum, B., Weitz, C.J., 2011. An intrinsic circadian clock of the pancreas is required for normal insulin release and glucose homeostasis in mice. Diabetologia 54, 120-124.

Salgado-Delgado, R.C., Saderi, N., Basualdo Mdel, C., Guerrero-Vargas, N.N. Escobar, C., Buijs, R.M., 2013. Shift work or food intake during the rest phase promotes metabolic disruption and desynchrony of liver genes in male rats. PLOS ONE 8 e60052.

Sanchez, J., Oliver, P., Pico, C., Palou, A., 2004. Diurnal rhythms of leptin and ghrelin in the systemic circulation and in the gastric mucosa are related to food intake in rats. Pflugers Arch 448, 500-506.

Scheer, F.A., Buijs, R.M., 1999. Light affects morning salivary cortisol in humans J. Clin. Endocrinol. Metab 84, 3395-3398.

Scheer, F.A., Hilton, M.F., Mantzoros, C.S., Shea, S.A., 2009. Adverse metabolic and cardiovascular consequences of circadian misalignment. Proc. Natl. Acad. Sci. U.S.A. $106,4453-4458$

Schlierf, G., Dorow, E., 1973. Diurnal patterns of triglycerides, free fatty acids, blood sugar, and insulin during carbohydrate-induction in man and their modification by nocturnal suppression of lipolysis. J. Clin. Invest 52, 732-740.

Schmutz, I., Ripperger, J.A., Baeriswyl-Aebischer, S., Albrecht, U., 2010. The mammalian clock component PERIOD2 coordinates circadian output by interaction with nuclear receptors. Genes Dev 24, 345-357.

Schoeller, D.A., Cella, L.K., Sinha, M.K., Caro, J.F., 1997. Entrainment of the diurna rhythm of plasma leptin to meal timing. J. Clin. Invest 100, 1882-1887.

Schippers, K.J., Nichols, S.A., 2014. Deep, dark secrets of melatonin in animal evolution. Cell 159, 9-10.

Scott, E.M., Carter, A.M., Grant, P.J., 2008. Association between polymorphisms in the Clock gene, obesity and the metabolic syndrome in man. Int. J. Obes. (Lond) $32,658-662$.

Shapiro, D.J., Rodwell, V.W., 1969. Diurnal variation and cholesterol regulation of hepatic HMG-CoA reductase activity. Biochem. Biophys. Res. Commun 37, $867-872$.

Shimba, S., Ishii, N., Ohta, Y., Ohno, T., Watabe, Y., Hayashi, M., et al., 2005. Brain and muscle Arnt-like protein-1 (BMAL1), a component of the molecular clock, regulates adipogenesis. Proc. Natl. Acad. Sci. U.S.A. 102, 12071-12076.

Shimba, S., Ogawa, T., Hitosugi, S., Ichihashi, Y., Nakadaira, Y., Kobayashi, M., et al. 2011. Deficient of a clock gene, brain and muscle Arnt-like protein-1 (BMAL1), induces dyslipidemia and ectopic fat formation. PLoS ONE 6 e25231.

Shostak, A., Meyer-Kovac, J., Oster, H., 2013. Circadian regulation of lipid mobilization in white adipose tissues. Diabetes 62, 2195-2203.

Sladek, M., Rybova, M., Jindrakova, Z., Zemanova, Z., Polidarova, L., Mrnka, L., et al., 2007. Insight into the circadian clock within rat colonic epithelial cells. Gastroenterology 133, 1240-1249.

Sobrino Crespo, C., Perianes Cachero, A., Puebla Jimenez, L., Barrios, V., Arilla Ferreiro, E., 2014. Peptides and food intake. Front. Endocrinol. (Lausanne) 5, 58

Sookoian, S., Gemma, C., Fernandez Gianotti, T., Burgueno, A., Alvarez, A., Gonzalez, C.D., et al., 2007. Effects of rotating shift work on biomarkers of metabolic syndrome and inflammation. J. Intern. Med 261, 285-292.

Sookoian, S., Gemma, C., Gianotti, T.F., Burgueno, A., Castano, G., Pirola, C.J., 2008 Genetic variants of Clock transcription factor are associated with individual susceptibility to obesity. Am. J. Clin. Nutr 87, 1606-1615.

Stavinoha, M.A., Rayspellicy, J.W., Hart-Sailors, M.L., Mersmann, H.J., Bray, M.S., Young, M.E., 2004. Diurnal variations in the responsiveness of cardiac and skeletal muscle to fatty acids. Am. J. Physiol. Endocrinol. Metab 287, E878-E887.

Stephan, F.K., Zucker, I., 1972. Circadian rhythms in drinking behavior and locomotor activity of rats are eliminated by hypothalamic lesions. Proc. Natl. Acad. Sci. U.S.A. 69, 1583-1586.

Stokkan, K.A., Yamazaki, S., Tei, H., Sakaki, Y., Menaker, M., 2001. Entrainment of the circadian clock in the liver by feeding. Science 291, 490-493.

Su, Y., van der Spek, R., Foppen, E., Kwakkel, J., Fliers, E., Kalsbeek, A., 2014. Effects of adrenalectomy on daily gene expression rhythms in the rat suprachiasmatic and paraventricular hypothalamic nuclei and in white adipose tissue. Chronobiol. Int $1-14$.

Tabuchi, S., Tsunematsu, T., Black, S.W., Tominaga, M., Maruyama, M., Takagi, K. et al., 2014. Conditional ablation of orexin/hypocretin neurons: a new mouse model for the study of narcolepsy and orexin system function. J. Neurosci 34 6495-6509.

Teboul, M., Guillaumond, F., Grechez-Cassiau, A., Delaunay, F., 2008. The nuclear hormone receptor family round the clock. Mol. Endocrinol 22, 2573-2582.

Tousson, E., Meissl, H., 2004. Suprachiasmatic nuclei grafts restore the circadian rhythm in the paraventricular nucleus of the hypothalamus. J. Neurosci 24
$2983-2988$

Tsai, J.Y., Kienesberger, P.C., Pulinilkunnil, T., Sailors, M.H., Durgan, D.J., VillegasMontoya, C., et al., 2010. Direct regulation of myocardial triglyceride metabolism by the cardiomyocyte circadian clock. J. Biol. Chem 285, 2918-2929.

Tsai, J.Y., Villegas-Montoya, C., Boland, B.B., Blasier, Z., Egbejimi, O., Gonzalez, R. et al., 2013. Influence of dark phase restricted high fat feeding on myocardial adaptation in mice. J. Mol. Cell. Cardiol 55, 147-155.

Tsang, A.H., Barclay, J.L., Oster, H., 2013. Interactions between endocrine and circadian systems. J. Mol. Endocrinol 52, R1-R16.

Tsutsumi, K., Inoue, Y., Kondo, Y., 2002. The relationship between lipoprotein lipase activity and respiratory quotient of rats in circadian rhythms. Biol. Pharm. Bull $25,1360-1363$.

Turek, F.W., Joshu, C., Kohsaka, A., Lin, E., Ivanova, G., McDearmon, E., et al., 2005. Obesity and metabolic syndrome in circadian Clock mutant mice. Science 308, 1043-1045.

Um, J.H., Yang, S., Yamazaki, S., Kang. H., Viollet, B., Foretz, M., et al., 2007. Activation of 5'-AMP-activated kinase with diabetes drug metformin induces casein kinase Iepsilon (CKIepsilon)-dependent degradation of clock protein mPer2. J. Biol. Chem 282, 20794-20798.

van Raalte, D.H., Ouwens, D.M., Diamant, M., 2009. Novel insights into glucocorticoid-mediated diabetogenic effects: towards expansion of therapeutic options? Eur. J. Clin. Invest 39, 81-93.

Valassi, E., Scacchi, M., Cavagnini, F., 2008. Neuroendocrine control of food intake. Nutr. Metab. Cardiovasc. Dis 18, 158-168.

Van Cauter, E., Polonsky, K.S., Scheen, A.J., 1997. Roles of circadian rhythmicity and sleep in human glucose regulation. Endocr. Rev 18, 716-738.

Verhagen, L.A., Pevet, P., Saboureau, M., Sicard, B., Nesme, B., Claustrat, B., et al., 2004. Temporal organization of the 24-h corticosterone rhythm in the diurnal murid rodent Arvicanthis ansorgei Thomas 1910. Brain Res 995, 197-204.

Vieira, E., Marroqui, L., Batista, T.M., Caballero-Garrido, E., Carneiro, E.M., Boschero, A.C., et al., 2012. The clock gene Rev-erbalpha regulates pancreatic beta-cell function: modulation by leptin and high-fat diet. Endocrinology 153, $592-601$.

Weaver, D.R., 1998. The suprachiasmatic nucleus: a 25-year retrospective. J. Biol. Rhythms 13, 100-112.

Woldt, E., Sebti, Y., Solt, L.A., Duhem, C., Lancel, S., Eeckhoute, J., et al., 2013. Rev-erbalpha modulates skeletal muscle oxidative capacity by regulating mitochondrial biogenesis and autophagy. Nat. Med 19, 1039-1046.

Woon, P.Y., Kaisaki, P.J., Braganca, J., Bihoreau, M.T., Levy, J.C., Farrall, M., et al., 2007. Aryl hydrocarbon receptor nuclear translocator-like (BMAL1) is associated with susceptibility to hypertension and type 2 diabetes. Proc. Natl. Acad. Sci. U.S.A. $104,14412-14417$

Wu, X., Xie, H., Yu, G., Hebert, T., Goh, B.C., Smith, S.R., et al., 2009. Expression profile of mRNAs encoding core circadian regulatory proteins in human subcutaneous adipose tissue: correlation with age and body mass index. Int. J. Obes. (Lond) 33 $971-977$.

Xu, B., Kalra, P.S., Farmerie, W.G., Kalra, S.P., 1999. Daily changes in hypothalamic gene expression of neuropeptide Y, galanin, proopiomelanocortin, and adipocyte leptin gene expression and secretion: effects of food restriction. Endocrinology $140,2868-2875$.

Yamamoto, H., Nagai, K., Nakagawa, H., 1987. Role of SCN in daily rhythms of plasma glucose, FFA, insulin and glucagon. Chronobiol. Int 4, 483-491.

Yamazaki, S., Numano, R., Abe, M., Hida, A., Takahashi, R., Ueda, M., et al., 2000. Resetting central and peripheral circadian oscillators in transgenic rats. Science 288, 682-685.

Yang, J.N., Wang, Y., Garcia-Roves, P.M., Bjornholm, M., Fredholm, B.B., 2010. Adenosine $A(3)$ receptors regulate heart rate, motor activity and body temperature. Acta Physiol. (Oxf.) 199, 221-230.

Yang, S., Liu, A., Weidenhammer, A., Cooksey, R.C., McClain, D., Kim, M.K., et al., 2009. The role of mPer2 clock gene in glucocorticoid and feeding rhythms. Endocrinology 150, 2153-2160.

Yannielli, P.C., Molyneux, P.C., Harrington, M.E., Golombek, D.A., 2007. Ghrelin effects on the circadian system of mice. J. Neurosci 27, 2890-2895.

Yi, C.X., Challet, E., Pevet, P., Kalsbeek, A., Escobar, C., Buijs, R.M., 2008. A circulating ghrelin mimetic attenuates light-induced phase delay of mice and lightinduced Fos expression in the suprachiasmatic nucleus of rats. Eur. J. Neurosci $27,1965-1972$

Yi, C.X., Serlie, M.J., Ackermans, M.T., Foppen, E., Buijs, R.M., Sauerwein, H.P., et al., 2009. A major role for perifornical orexin neurons in the control of glucose metabolism in rats. Diabetes 58, 1998-2005.

Yin, L., Wu, N., Curtin, J.C., Qatanani, M., Szwergold, N.R., Reid, R.A., et al., 2007. Reverbalpha, a heme sensor that coordinates metabolic and circadian pathways. Science 318, 1786-1789.

Yoo, S.H., Yamazaki, S., Lowrey, P.L., Shimomura, K., Ko, C.H., Buhr, E.D., et al., 2004. PERIOD2:LUCIFERASE real-time reporting of circadian dynamics reveals persistent circadian oscillations in mouse peripheral tissues. Proc. Natl. Acad. Sci. U.S.A. 101, 5339-5346.

Zani, F., Breasson, L., Becattini, B., Vukolic, A., Montani, J.P., Albrecht, U., et al., 2013. PER2 promotes glucose storage to liver glycogen during feeding and acute fasting by inducing Gys2 PTG and G L expression. Mol. Metab 2, 292-305.

Zawilska, J.B., Santorek-Strumillo, E.J., Kuna, P., 2010. Nighttime eating disorders-clinical symptoms and treatment. Przegl. Lek 67, 536-540.

Zhang, D., Tong, X., Arthurs, B., Guha, A., Rui, L., Kamath, A., et al., 2014. Liver clock protein BMAL1 promotes de novo lipogenesis through insulin-mTORC2-AKT signaling. J. Biol. Chem 289, 25925-25935. 
Zhang, E.E., Liu, Y., Dentin, R., Pongsawakul, P.Y., Liu, A.C., Hirota, T., et al., 2010. Cryptochrome mediates circadian regulation of cAMP signaling and hepatic gluconeogenesis. Nat. Med 16, 1152-1156.

Zhang, S., Zeitzer, J.M., Yoshida, Y., Wisor, J.P., Nishino, S., Edgar, D.M., et al., 2004. Lesions of the suprachiasmatic nucleus eliminate the daily rhythm of hypocretin-1 release. Sleep 27, 619-627.
Zhao, Y., Zhang, Y., Zhou, M., Wang, S., Hua, Z., Zhang, J., 2012. Loss of mPer2 increases plasma insulin levels by enhanced glucose-stimulated insulin secretion and impaired insulin clearance in mice. FEBS Lett 586, 1306-1311.

Zulley, J., Wever, R., Aschoff, J., 1981. The dependence of onset and duration of sleep on the circadian rhythm of rectal temperature. Pflugers Arch 391, 314-318. 